\title{
Attitudes and Intentions Related to Adoption of the HPV Vaccine among Adolescent Girls and their Mothers in Akinyele Local Government Area of Oyo State
}

\author{
Article by Ukwo Joy Michael \\ Master of Public, Texila American University, Nigeria \\ Email: michael.ukwojoy@texilaconnect.com
}

\section{Introduction}

\subsection{Background information}

Cancer of the cervix is the second most common cancer and the second leading cause of cancer deaths in women worldwide (WHO, 2004, Schoell, Janicek, Mirhasshemi 1999). Each year an estimated 500,000 cases are newly diagnosis (WHO, 2004, schoell et .al 1999), a significant proportion of which will be in advanced stage (Guidozzi, 1999). In developing countries, it is the most commonly occurring type of cancer among women, accounting for $80 \%$ of the cases (WHO, 2004, Guidozzi, 1996). Cervical cancer is one of the most common cancers affecting U.S. women - now ranks 14 in frequency in this population (Armstrong .C, 2007). In 2007, an estimated of 11,150 women in the United States was diagnosed with cervical cancer, and an estimated 3,670 die of this disease (Armstrong .C, 2007). The lifetime risk of cervical cancer was estimated at $3.7 \%$ in the absence of cervical cancer screening (Brabin L et. al 2006).

Worldwide, especially in middle and low income countries, cervical cancer is the second most common cancer in women after breast cancer, and the third most frequent cause of cancer death, accounting for nearly 300,000 deaths annually(Cavalli F, et.al 1997). In high income countries, the availability of Pap smear and treatment has drastically reduced the incidence of cervical cancer. By contrast, up to $80 \%$ of the estimated 280,000 annual deaths from cervical cancer worldwide occur in developing countries. In these countries, about $95 \%$ of women will never have Pap smear or related prevention and treatment options in their lifetime (Babarinsa, I. et .al, 1998). Sub-Saharan Africa has by far the highest burden and mortality associated with cervical cancer in the world. A total of 5318 new cases of cervical cancer were detected in South Africa in 1997, while the risk of development of cervical cancer in South African women has been estimated to be 1 in 291 (Chirenje M. Z et.al, 2005). In Nigeria, the estimated incidence rate of cervical cancer is 25 per 100,000 women; with an estimated 8000 new cases of cervical cancer diagnosed in the country each year (Adewole I. F et.al 2005).

Equally high rates of cervical cancer have been reported from several African countries including Uganda, Malawi, Ethiopia and Kenya. Report indicate that while a woman in the United States has a $70 \%$ chance of surviving cervical cancer, that chance is reduced to $58 \%$ in Thailand, to $42 \%$ in India, and to only $21 \%$ in sub-Saharan Africa(WHO 2000, Chirenje M. Z et.al, 2005). By contrast to the high burden and mortality associated with cervical cancer in Africa, very few primary and secondary prevention initiatives are currently available to curtail the disease in Africa. To date, cervical cancer screening like Pap smear had significantly reduced the rates of cervical cancer in high and middle income countries, but this still poorly utilized in Africa. Part of the low acceptance of secondary prevention services for cervical cancer in Africa is due to the lack of awareness of cervical cancer and the role of screening, inappropriate health seeking behavior by women, poor organization of health services and the low priority accorded to women's health by policymakers. 
South American Journal of Public Health

Special Edition May 2016

\subsection{Human papiloma virus and cervical cancer}

Epidemiological studies relating genital herpetic infection to cervical cancer have been reported the role of human papilloma virus (HPV) as a causative agent of cervical cancer is well established and the detection of HPV types 16 and 18, predominantly, carry prognostic importance in some studies (Nahmias A. $J$ et al 1974). It was also observed that HPV 16 predominated in squamous-cell carcinoma, whereas in adenocarcinoma and adenosquamous carcinoma HPV 18 predominated. Another research carried out in Ibadan in south west Nigeria revealed a high prevalence of human papiloma virus (HPV), a necessary cause of cervical cancer, found in all the different age groups in the study population(Thomas, Herreno, Omigbodun, Ojemainde, Ajayi, Fawole, Oladepo, Smith, Arsken, Munoz, Snjiders, Meijer and Francechis, 2004). Research conducted by National Institute of Health and other investigators throughout the 1980s and 1990s demonstrated that virtually all cases of cervical cancer are caused by persistent infection with specific types of human papillomavirus (HPV), which can be transmitted by sexual contact. There are more than 100 types of HPV of the 15 types that are considered to be cancer-causing, or oncogenic, HPV types 16 and 18 are responsible for about $70 \%$ of cervical cancers worldwide. In most women infected with HPV, however, the infection will resolve and cervical cancer will not develop; therefore, HPV infection is necessary but not sufficient for development of the disease.

\subsection{Problem statement}

Cervical cancer is an important women's reproductive health problem especially in developing countries (program for appropriate technology in health PATH, 2000). It kills more than 250,000 women each year worldwide and disproportionately affects the poorest, most vulnerable women in developing countries (ACCP, 2002). Cervical cancer has remained the second commonest female cancer since 1995 and the commonest genital tract cancer- for $63 \%$ of cancers at the U. C. H. (Babarinsa et al. 2000, Akinremi, 2004). About 12\% of women in Southwest Nigeria had pre-cancerous cervical lesions (Ayinde et al 2005). Every 10 minutes, a woman in Africa dies from cervical cancer despite the fact that almost every case is preventable through a programme of screening, treatment and vaccination against the Human Papilloma Virus (HPV) which has been incriminated as a leading risk factor which is gotten through sexual contact (WHO 2007). A summary of the 1989 to 1996 cancer registries report showed that cervical cancer had a relative ratio frequency of $23.1 \%$ (Ogunbiyi, 2000)compare to other malignancies. Recently, the Ibadan cancer registry reported that cancer of the cervix constitutes $21.3 \%$ of all female malignancies with about 5- 6 cases seen every week (Akinremi, 2004). Data from Eruwa, a rural area in south - western Nigeria reported cervical cancer as the commonest malignant tumor among female (Jaiyeola, 2000). In Jos, in north central Nigeria, it accounted for $77.0 \%$ of the gynecological cases between January 1990 and December 1999(Madong, and Ujah, 2003). Similarly in Maiduguri, a town in North-eastern Nigeria, it was found to be the commonest malignant tumor of the female genital tract (Kpari, Nggada, and Mairga 2004). In Nigeria early sexual debut has been reported among adolescent girls at age 12. A study done in southwest Nigeria show that there is an increased cervical cancer prevalence and incidence with an increased of $26.3 \%$ of screened women come up with leisure. While $24.3 \%$ of women with cervical leisure are young women and are presented with multiple HPV type (Thomos, Herreno, Omigbodun, Ojemakinde, Ajayi, Fawole, Oladepo, Smith, Arsken, Munoz, Snijders, Meijer and Francechis, 2004). While 33.4\% of women come up with of HPV 16, 31, 35, 58 sub types predominate. The HPV subtype can enhance the persistent DNA and also contribute to cervical cancer among young women. If nothing is done both incidence and prevalence with remain high in the region (Thomos, Herreno, Omigbodun, Ojemakinde, Ajayi, Fawole, Oladepo, Smith, Arsken, Munoz, Snijders, Meijer and Francechis, 2004).

Currently in Nigeria, less than $10 \%$ of women are screened (Babarinsa and Adewole, 1996; Ajayi and Adewole, 1998) while about 40 to 50\% of women are screened in developed countries. Most time the women come to hospital with invasive cancer of the cervix at 
advanced stages when radiotherapy is of little or no benefit and even radical hysterectomy is of no benefit. Because even thought the screening service is effective they are not being utilized due to cost and technical procedure of testing and cultural barrier. But the window of opportunities therefore is the HPV vaccine as it being used in the USA and it was found to reduce the chance of cervical cancer. HPV Vaccine is being considered for developing countries like Nigeria, but there is need to check it acceptance by mothers and their adolescent between the ages of $10-16$ years in the uptake of the vaccine. As there is paucity of information regarding the knowledge, intensions and experiences of Adolescent girls and biological mothers towards uptake of HPV vaccine, yet these are necessary for designing appropriate interventions aimed at enhancing the uptake of HPV vaccine. So therefore there is a need to effectively combine the use of screening services with the HPV vaccination. The vaccination has a single dose and has no technically involve in use as compare to the screening service. This study therefore seeks to assess the knowledge, willingness and experiences of Adolescent girls and biological mothers towards cervical cancer prevention with special reference to the uptake of HPV vaccine and other cervical cancer prevention options.

\subsection{Justification}

Cervical cancer is deadly yet preventable disease condition in women. Well organized cervical screening has been show to be effective in the reduction of the both it morbidity and mortality (Park, 2002). Despite this, screening rate in developing countries are generally as low as $5 \%$ due to the low level of awareness of the available screening service, cost of the service, bad health seeking behaviors and the technicality surrounding the screening service (Akinremi, 2004). So there is need to combine the HPV vaccination program with screening service as a more comprehensive prevention method. Therefore there is a need to access the attitude and willingness of mothers and biological daughter toward the uptake of the HPV vaccine. It is also important to access factors that can influence the decision to take the vaccine or not to take the vaccine among mothers and daughters in the community and determine the best communication strategy in the dissemination of the HPV vaccine information. This study is justified based on the fact that it has potential for yielding baseline information regarding the attitude and willingness of adolescent girls in the uptake of HPV vaccine. It also has latent for yielding evidence based information needed for designing appropriate intervention aimed at uptake of HPV vaccine. The study also has potentials of giving insights into the interplays between attitude, willingness and previous immunization experience towards HPV vaccine uptake and key variables such as age, level of educational qualification, social class and cultural background. It will also yield information regarding the best form of communication strategy that should use in dissemination of information in ensuring the up taking of the HPV vaccine when made available. This study is also significant because it deal with women health, which has been receiving global attention in recent time. Women greatly influence the growth and development of children especially in the African society. Any study therefore that of affecting the health of women positively should be encourage, since preserving a women life is preserving a whole community(Fonn, 1997). Lastly findings of this study have latent for informing policy formulation aimed at aggrandizing cervical cancer prevention especially the uptake of the vaccine in Nigeria.

\subsection{HPV Vaccination}

In June 2006, The U. S. Food and Drug Administration approved the vaccine called Gardasil, a quadrivalent human papillomavirus recombinant vaccine for women 10 to 14 years for prevention of cervical cancer caused by HPV types 6, 11, 16, and 18. The vaccine prevents infection against the two types of HPV responsible for the majority of cervical cancer cases (Olshen E, et .al 2004). This is an exciting development and a landmark decision, heralded as a major advance in the prevention of cervical cancer that may have a worldwide impact on the incidence of this malignancy. Human Papilloma Virus 
South American Journal of Public Health

Special Edition May 2016

(HPV)vaccine has undergone successful trials and has recently been approved for use for the primary prevention of cervical cancer(Dell DL, et .al 2000) This study is to determine attitude and willingness of adolescent girls and their mothers towards HPV vaccination when made available; unlike other cancerous ailments the cervical cancer is 100 percent preventable with effective utilization of screening service with the use of vaccination programme (Hanson Okoh December 17, 2008). Studies have shown that the vaccine appears to prevent earlystage cervical cancer and precancerous lesions (Dell DL, et .al 2000). In Nigeria however, there are no national policy or guidelines in targeted toward cervical cancer prevention and widespread cervical screening for women is limited. However, the good news is the increasing evidence now available in the literature which indicates that a vaccine directed against the human papillomavirus the causative agent of cervical cancer can reduce the incidence of cervical cancer pre-lesions that lead to cervical cancer. In October 2005, Merck \& Co., Inc. announced the results of its phase III trial on its vaccine, Gardasil. The study which enrolled over 12000 women in 13 countries, demonstrated the nearly $100 \%$ prevention of noninvasive cervical cancers in women who received the vaccine. Similarly, GlaxoSmithKline's Cervarix T M is undergoing Phase III trials, and has so far produced impressive reports. The Gardasil R M is now licensed in more than 45 countries for use in 10 to 16 year old girls. Human Papilloma Virus (HPV)vaccine has undergone successful trials and has recently been approved for use for the primary prevention of cervical cancer.

The Independent Policy programme at The National Institute of Social and Economic Research concluded that Nigeria losses 56.5-78.5 billion Naira each year to all cancers (Akinwumi, 2004). HPV vaccine need to be introduced in the framework of comprehensive cervical cancer control, and offers an opportunity to bring together a wide range of constituents who have not to date worked closely on vaccination. Ultimately, the decision of whether and when a vaccine will be introduced will depend on individual countries. To prepare for decisions on HPV vaccine use, the sexual and reproductive health (SRH; including adolescent health), immunization, and cancer control communities need to work together to analyze the appropriate data and build international and national consensus. The timeframe for other newer vaccines, such as hepatitis Bhas been measured in decades, and the challenge to the public sector is to greatly shorten the time needed to make HPV vaccines available and affordable for the developing world, where their impact will be greatest. Right now, the HPV vaccine (called Gardasil) is only given to females ages 10 to 16 . The vaccine is given in three doses (shots) over a six-month period. Women who are pregnant should not get the HPV vaccine until after the baby is born. The HPV vaccine works best in females who haven't been exposed to the virus. It protects against four types of HPV. Studies show the vaccine prevents about 70 percent of cervical cancers if it is given to women and girls before they have sex for the first time. It also protects against about 90 percent of genital warts. The shot works for at least five years, maybe longer as it is still under study. Gro Harlem Brundtland, the World Health Organization (WHO) Secretary General agrees that all nations should prevent cervical cancer as an investment in humankind, global and national economy. It is an investment into the nation's and families' fortunes and future.

\subsection{Research question}

The research questions which govern the conduct of this research are as follows;

1. What are the experiences of mothers from previous immunization services that could influence the uptake of HPV vaccine

2. What is the attitude mothers and adolescent girls toward the HPV vaccine

3. What is the willingness of mothers and daughter the uptake of the HPV vaccine

4. What are the communication strategies that can be best employ in the community to ascertain the uptake of HPV vaccine 


\subsection{Hypotheises}

1. There is no significant difference between attitude and willingness of adolescent girls and mothers toward the uptake of the HPV vaccine.

2. There is no significant relationship between level of knowledge and willingness of adolescent girls and mothers in the uptake of HPV vaccine

3. There is no significant relationship between previous immunization experience take by adolescent girls and mothers and the willingness to take the HPV vaccine

\subsection{Board objective:}

The board objective of this study is to document the attitude and willingness of adolescent girls and their mothers toward the uptake of HPV vaccine.

\subsubsection{Specific objective}

1. To document experiences of mothers from previous immunization service that could influence the uptake of HPV vaccine

2. To determine the attitude of adolescent girls and mothers toward the uptake of HPV vaccine

3. To determine the willingness of mothers and adolescent girls in the uptake of HPV vaccine

4. To assess the level of knowledge of cervical cancer prevention and HPV vaccine among adolescent girls and mothers in Akinyele LGA

5. To determine the communication strategy that will be best employ in disseminate HPV vaccine program in the community

\section{Review of literature}

\subsection{Background information on cancer of the cervix:}

The cervix is the cylindrical, narrow inferior part of the uterus. Which protrudes to the uppermost part of the vagina? Located between the bladder and the rectum, it is the structure that dilates during childbirth to allow the baby to transverse the birth canal (Rich, 2002). While Cancer is an excessive, uncontrolled growth of abnormal cells, which invade (spreads from its primary site to another part (secondary site)in the body)and destroy other tissues. But the sites of occurrence determine the severity and certain type of cancer are more life threatening than others. Cervical cancer develops in lining of the cervix and occurs when cells in the cervix grow erratically and multiply out of control (Imaginis, 2004).

There are two main cancers that develop from the cervix: squamous cell cancers and adenocainomas (Rich, 2002), squamous cell cancer develops in flat scaly surface that line the cervix while adenocarcinomas develop in the galandular surface cells (principle of health on the net foundation HON, 2004). About $80 \%$ of cervical cancers are squamous cell cancer and the reminders $20 \%$ are adencarcinomas (Rich, 2002). Cervical cancer occurred among women of reproductive age who are sexual active (Akinremi, 2000) Cervical cancer continues to be a significant health threat to women, cervical cancer is currently the fifth most deadly cancer in women worldwide (World Health Organization, 2009). In 2009, an estimated 4070 new cases of cervical cancer and 380 deaths occurred in Canada (Canadian Cancer Society, 2009). Cervical cancer is largely preventable by effective screening programmes and considerable reduction in cervical cancer incidence and deaths has been achieved in developed nations with systematic cytological smear screening programmes. The screening services have not been possible in most low resource settings including Nigeria. The only available activity has been to use opportunistic screening of those women who come to the health units for other reasons. Screening the women then becomes the responsibility of the medical worker who should know those eligible. It is known that precancerous lesions are detectable for 10 years or more before cancer develops. An important safeguard against cervical cancer is the HPV vaccine and Pap test, which involves scraping cells from the 
South American Journal of Public Health

Special Edition May 2016

cervix during a vaginal speculum examination. The steady decline in the incidence and mortality of cervical cancer in Canada for the past three decades is largely attributed to widespread Pap testing. (Canadian Cancer Society; 2009) Cervical cancer is the commonest malignancy of women in Uganda with over $80 \%$ of patients diagnosed with cervical cancer in Mulago hospital present with advanced disease. West African Women have continually remained at high risk due to some risk factors. Most important risk factor is infrequent cervical screening or lack of accessible cervical screening services for women. Also others risk factors are the Early age at sexual contact, Human Papilloma Virus infection, Early marriage below age 20 years, Multiple partners and polygamy and Multiparty among Africa women.

\subsection{Incidence and prevalence rate of cervical cancer}

The first observations related to the incidence of cancer of the cervix are traditionally attributed to (Rigoni- Stern, 1842), an Italian physician who examined the records of deaths in Verona, Italy, from 1760 to 1839 . He noted that the prevalence of cervical cancer was higher in married than in unmarried women and that the rate increases steadily between the ages of 30 and 60 years. He also noted that uterine cancer was less common in unmarried women and was extremely rare in nuns (Meanwell et.al, 1991)states that Rigoni-Stern 'remark relate to breast cancer; he attribute the observation of a sexual link in the etiology of cervical cancer (Logan, 1953), who stated that the lowest rates of cervical cancer were among single women and the highest rates among porous and widowed women. Also in 1906, Vineberg indicated that Jewish women had a decrease incidence of cervical cancer despite being a part of the lower socioeconomic classes. From his case records between 1893 and 1906, Vineberg observed a 20-fold difference in the number of cases of cervical cancer in Non-Jewish as compared with Jewish women. The inference that circumcision of the Jewish males may be a contributing factor prompted the examination of other ethnic groups such as Moslems, who also practice circumcision. Cervical cancer is more common in Latin America and less frequent in Jewish and European women and Fiji Islanders (Hochma.et.al 1955).Although some researchers have attributed the low frequency of cervical carcinoma in Jewish women to the circumcision of Jewish men (Terris $M$, et al, 1973). This low incidence has not been demonstrated in sexual partners of non-Jewish circumcised men (Lynch et al, 1975)Although Ashkenazi women have an overall cancer risk comparable to other ethnic groups. It is still lower for carcinoma of the cervix, which occurs infrequently in Jewish women. Carcinoma of the uterine cervix can be induced in experimental animals by application of hormonal or other chemical carcinogens (Joneja MG). However, no definite evidence exists linking the use of oral contraceptives with carcinoma of the uterine cervix relation to mammary cancer, benign breast lesions and cervical cancer (Green J, et al, 2003).

Almost $80 \%$ of cervical cancer cases occur in developing countries and in many developing regions, cervical cancer is the most common cancer in women(WHO, 2004). Recent global data indicate that over half of the new case occur in Asia( Parkin, 2000). The highest age standardized rate are found in east Africa (WHO 2004). In all these regions, the rates are over 30 cases per 100,000 women. Bolivia, Guinea, Guyana, Haiti, Malawi, Nicaragua, Swaziland, united republic of Tanzania is the hardest hit with rate of over 50 cases per 100,000 women (WHO, 2004). Regional variations in incidence also occur in these countries with higher rate in rural and less developed area (Jaiyeola, Ojemakinde, and Izebvaye, 2002). The incidence and mortality vary widely between countries with up to fold difference between high and low risk and low risk area (Jaiyeola et.al, 2002). According to Harshad et al, February 2008, In sub- Saharan Africa, cervical cancer is the most common cancer of women in West, East, Central and southern Africa, cervical cancer account for an estimated $20-25 \%$ of all new cancers among women. An estimated number of new cervical cancers in some developing countries are shown below: Asia, 235,000 Africa, 69,000 Latin America/ Caribean, 77,000 


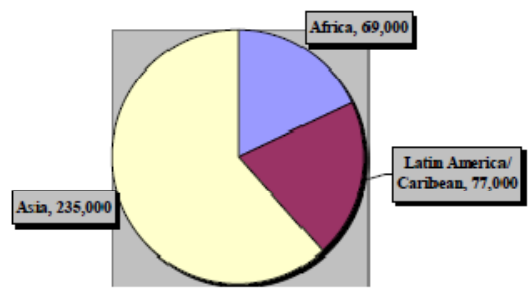

Figure 1 : Estimated number of new cervical cancer case in some developing regions, 2000 Source: Parkin, 2000

\subsubsection{Pathogenesis of cervical cancer:}

Cervical cancer develops in the lining of the cervix. It occurs when cells in the cervix grow erratically and multiply out of control (Imaginis, 2004). It is usually precede by a slowly progressive pre-invasive lesion called dysplasia (Sevin, 1999), which may occur after HPV infections as illustrated in the figure below (figure 2). Women are generally infected with HPV in their teens, twenties, or thirties although cervical cancer can develop 20 years or more after HPV infection (PATH, 2002). The exact proportion of cases progressing to invasive carcinoma from pre-invasive stage is not known. There is evidence that some dysplasia spontaneously regress by direct extension into the lymph node and pelvis organs (Park, 2002). The clinically stage at presentation with cervical cancer varies, with developed countries recording more localized disease $(51 \%)$ and more advance disease in older women(Jaiyola, Ojemakinde, Izebvaye, 2002). In Nigeria however, like in most developing countries, cases are diagnosed predominantly at advanced stage (Jaiyeola et al, 2002).

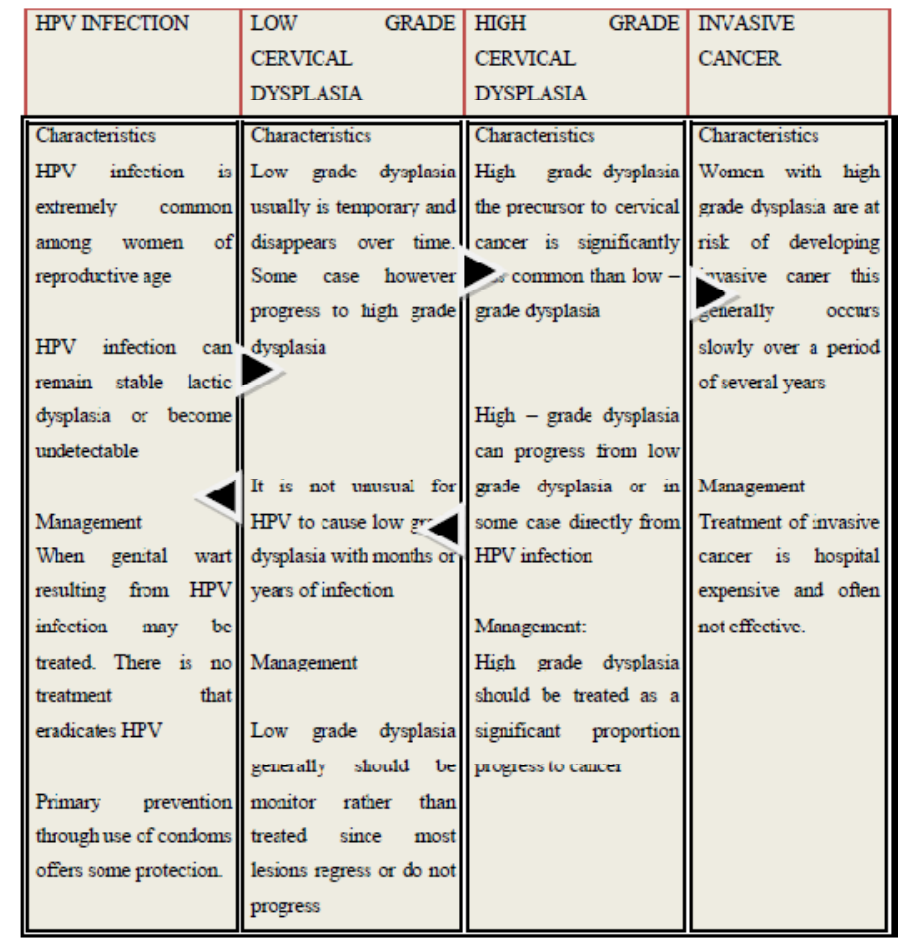

Figure 2: Natural History of cervical cancer and program implications Source: PATH 2000.

\subsubsection{Incidence and cervical cancer burden in Nigeria}

Cervical cancer affects women who are 30 years and above, it is the commonest cancer of women in Calabar, Zaria and Eruwa (Dr. A.A.F. Banjo 2004). Cervical cancer is common in Nigeria because there is poor awareness of this disease even among healthcare workers, no 
South American Journal of Public Health

Special Edition May 2016

effective screening programme (Harshad et al, February 2008)and Human Immune Deficiency Virus (HIV) and Human Papiloma Virus (HPV) infections increases susceptibility to the disease. More than 274,000 women die of cervical cancer has some form of history in the HIV infection. Cervical cancer affects women of all ages who are sexually active and it is the commonest cancer of women who are in their reproductive age (Banjo, 2004). About 60\% of population mostly in rural areas has no access to cervical screening service (Banjo, 2004). Though the virus has various stereotypes; the most dangerous are 16 and 18 . At the viral stage, the treatment could be effected within short time after screening. But the disease can only be treated through radiotherapy and this does not guarantee full treatment and survival of the victim. More so in Nigeria there are only five centers with such medical facilities LUTH, UCH, Ahmadu Bello University, Zaria, Eko Hospital and the National Hospital, Abuja. This means that a woman found to be suffering from cervical cancer in the South East has to travel all the way to such states with the facilities. According to Eguwuonwu, testimonies abound of women who are left to die in the villages when their families consider the high cost of accessing radiotherapy. Sometimes due to ignorance, the women are thought to have been spiritually afflicted. Many women in Nigeria continue to suffer from cervical cancer because they lack knowledge about the existence, the modes of transmission, presentation, and the means of its prevention, the risk factors and the complication of the disease. So, majority of women present late when little opportunity for curative treatment are available and no there are no access to palliative care. It has assumed greater prominence with the increase in deaths due to infective causes and the increase in the incidence of HPV Infection, which is a predisposing factor.

A significant drop in its incidence has been recorded in the developed countries as a result of intensive program of cervical screening with the complimentary role of the Vaccination programmes introduce (1980s Elovainio L, Nieminen et.al 1997). The challenge of having inadequate centre in country may also have contributed to the growing cases of women who get affected by the disease. In the Northern part of the country, for example, cases of cervical cancer are more rampant due to early marriages. It is more common in the north than in the South because a girl who contracts the virus at the age of 14 is 16 times more likely to have it than girl infested by it at 29 years because at that time, the body is multiplying rapidly and we know that there; they marry at a very young age. Even when they have the opportunity to screen or go for treatment, it becomes more difficult, as the listopathologists, who specialize in cervical cancer treatment are very few (Dr. Eguwuon, NCCP). According to WHO reports that if women are screen once in their life time, it would drastically reduce the rate of incidence of the disease? If they are screen twice, there is a $74 \%$ chance of protection and reduction in such cases. But Nigerian women are not keen about submitting themselves for tests because they do not know that they are susceptible to it, also religious beliefs, cultural beliefs and Stigmatization is one of the reasons why women refuse to undergo screening. Cervical cancer need not be fatal because it is the easiest gynecologic cancer to be prevented through screening and early vaccination (Gynecologic Cancer Foundation (GCF)). A national cervical smear screening policy is being advocated for but in the interim, greater public education and the greater use of opportunistic screening complimented with the vaccination against HPV by physicians should be vigorously pursued if any significant progress will be made in reduction in the incidence rate. If HPV vaccination is to be introduced, parental acceptance will be crucial to ensuring a high uptake

\subsubsection{Mortality and mobility of cervical cancer}

Human papillomavirus (HPV)-related morbidity and mortality from cervical cancer primarily occurs in the developing world, where, unfortunately, access to vaccines in general and expensive newer vaccines in particular, is often more limited than in the industrialized world. In addition, secondary prevention methods such as HPV screening, Pap testing, or visual inspection are uncommon in the developing world, were present are not well utilized. The crude incidence rate globally is $16 / 100,000$ and $17.3 / 100,000$ in West Africa 
(International Agency for Research on Cancer (IARC)Globacom, 2002). WHO says about 85 percent of the estimated 493,000 new cases and over 273,000 deaths from cervical cancer occur in developing countries including Nigeria and that if not detected early, cervical cancer can be fatal(Ferlay et al. 2004). The American Cancer Society estimated that in 2007 there were 11,150 new cases of invasive carcinoma of the cervix in the United States and about 3,500 deaths, in addition to over 60,000 cases of carcinoma (Jemal A, et al 2006). However, cervical cancer is highly prevalent in developing nations; it is estimated that close to 500,000 women worldwide develop this tumor and 233,000 die of the disease (Jemal A, Siegel R, Ward E, et al). 10000 women are affected every year, out of which 8000 die the most susceptible are those between the ages 25 and 35 (Dr. Kin Eguwuonwu National Cervical Cancer Prevention Programme)

\subsubsection{Risk factor for cervical cancer}

The major risk factors are infrequent cervical screening or lack of accessibility to screening service, early sexual contact, multiparty i.e. having many children. Majority (60\%) of population in rural areas has no access to cervical screening service and the little less than $40 \%$ who have access do not utilized the service due to cost and technically of the procedure This condition usually develops over time(Dr. A.A.F. Banjo 2004). The level of awareness of cervical screening is low and worse still, is the level of uptake at the present. No significant impact will be made on reducing the incidence of cervical cancer focusing just on the screening service alone (Ezem B. U, 2007). Studying large number of women all over the world, researchers have identified certain risk factors that increase the chance that the cervix becoming abnormal or cancerous. It is believed that cervical cancer occurred when two or more risk factors act together (National Cancer Institute, 1994). The occurrence of cervical cancer has an evidence of the presence of Human Papiloma Virus; also there are some risk factors that increase the chance of contact or development of HPV. The cause of cervical cancer is not totally known (Rich 2002). As Current evidence suggests that the virus is necessary but not sufficient cause of the disease (Park. 2002).

\subsubsection{Human Papiloma Virus linked as Causation of Cervical Cancer}

Since 1970's it has been known that one of the causes of cervical cancer is through infection with Human Papiloma Virus (McIntyre P., 2005) subtypes of HPV causing malignant transformation of the cervical epithelium (McIntyre P. 2005, Lowndes CM, Gill OM, 2005). Epidemiological studies relating genital herpetic infection to cervical cancer have been reported (Nahmias A. J et al, 1974) the role of human papilloma virus (HPV) as a causative agent of cervical cancer is well established and the detection of HPV types 16 and 18, predominantly, carries prognostic importance in some studies. (J. Nat, 1995)noted that HPV 16 predominated in squamous-cell carcinoma, whereas in adenocarcinoma and adenosquamous carcinoma HPV 18 predominated. HPV is a virus that is passed from person to person through unprotected genital contact, most often during vaginal and anal sex (Wheeler CM, Mc Gough NS, et al, 2005). There are approximately one hundred different genotypes of HPV Forty of these types infect the genitalia, and fifteen put women at a high risk of cervical cancer (Peckham, Pinedo 1995). In the UK and many other countries, HPV 16 and 18 are the most common subtypes associated with cervical carcinoma and are believed to be implicated in the etiology of 70\% of malignancies (Lowndes CM, Gill OM 2005 Peckham, Pinedo 1995). It can take years for pre-cancerous changes to turn into cervical cancer. Patients with cervical cancer do not usually have problems until the cancer is advanced and has spread.

\subsubsection{Unprotected sexual contact and increased multiple partners}

Generally, sexually active women are risk of developing cervical cancer (Rich, 2002). Research has however shown that early exposure to sexual activity before age 16, a history of human papiloma virus( HPV) infection and other sexually transmitted disease increase the 
South American Journal of Public Health

Special Edition May 2016

risk of developing cervical cancer(NCI, 2004). A strong association has been reported between certain strain of the human papiloma virus and squamous cell cancers (Rich 2002, Wallin et. al, 1997). The human papiloma virus is sexually transmitted agent that infects the cells of the cervix and slowly cause cellular change that result in cervical cancer (Brosch et .al, 1997)approximately 80 different types of HPV exit. They can be divided into high risk types and low risk types (Nuovo, Melnikow, Howell, 2001). The fact that the HPV can be transmitted sexually (Brosch et.al, 1997). Program for appropriate technology in health PATH 2000) partly explain the association is further conformed by the fact that celibate women almost never develop squamous cervical cancer (Rich 2002). Moreover some studies have also show that the risk of being infected with HPV is reduced with the use of barrier contraceptive methods (Coker et.al, 1992). This however has been established. You are more likely to get HPV if you have multiple sexual partners. However, any woman who has ever had unprotected genital contact with another person is a risk of contacting HPV. Most women infected with HPV will not get cervical cancer.

An association between cigarette smoking and development of cervical cancer has been reported (Becker T M, 1999; Wheeler CM, Mc Gough NS, et al, 2005). Cigarette smoking by women is associated with increased risk of squamous cell cancer (Brinton, 1992). Smokers have been found to have a 50\% higher risk of developing cervical carcinoma than non smoker (America n Society of cytopathology ASC, 2002). A review of over 50 studies concluded that smoking was a cofactor for HPV infection and induction of cervical cancer (J. Epidemiology Biostatics 1998;3:229, 256). The risk appear to increase with the number of cigarette a women smokes each day, the number of years smoking(National cancer Institute 1994, Rich 20002)and use of unfiltered tobacco product (Ho, Kadish, Buch, Basu, Palan, Milehail, Rommey, 1998). But according to (Hugh M Shingleton et al, 1996, Harris et.al 1980)found a graded association between smoking and increased severity of cervical atypias, which persisted although weakened when the analysis was controlled for number of sexual partners, pregnancy and years of contraceptive use (Walboomer et.al, 1999).

\subsubsection{Male sexual partners visiting sex workers}

The role of men as sex partners in the etiology of cervical cancer has been described in many studies. A study in Bangkok revealed that women whose husband report frequent contact with sex worker(280 or more visit over their life time)were more than three more likely to develop invasive cancer than women whose husband reported no contact with sex worker. This was buttered by the fact that the women in the study reported their husband as their only partner throughout their life time (Thomas et .al 2001). Another study by Kjaer (1998)showed that a history of genital warts in males partners and non - use of condom were significant risk determinants of cervical neoplasia.

\subsubsection{Immunodeficiency and cervical cancer development}

Immunodeficiency is associated with higher rate of HPV infection and progression (ACS.2002).HPV infection, particularly in women with low CD4 counts is associated with high prevalence of HPV DNA and squamous intraepithelial lesion(SIL)detection(Maiman 1994, Ho et .al 1994, NCI, 1994; Palefsky et.al 1999, Akinremi 2004). An increase incidence of HPV is also associated with other immune - suppressed state such as organ transplant recipients, chronic renal failure, history of Hodgkin lymphoma and immunosuppressive therapy (ASC, 2002). As association between the use of oral contraceptive (the pill and cervical cancer particularly adenocarcinomas has also been reported by some research (Brinton 1991, Brinton 1992, Gan, Macaluso, Stalsberg, 1992, NCI 1994, Thomas and Ray, 1996, NCI, 2004). However this relationship is hard to prove since early exposure to sexual activity and having multiple sexual partners may be more common among women who use oral contraceptive (NCI 1994). Women whose mothers were given the drugs diethylstilbestrol (DES) during pregnancy to prevent miscarriage are also at increased risk (NCI, 1994). Multiple case control studies show an association between intake of some micronutrient and 
lower risk of cervical (NCI, 2004)several case control studies have investigate the effect of various micro nutrient on risk and have found that high dietary carotene (NCI, 1994)and possibly vitamin C(Grime and Economy, 1995)and E and foliate are associated with reduced risk for cervical cancer (Ziegler et.al 1990, Stattery et.al 1990, Mc Pherson, 1990). Knowledge of these risk factors and subsequent behavior change is necessary for the prevention of these cancers. One point however is worthy of note. No doubt, primary prevention of cervical cancer through preventing HPV present greater challenge than prevention for most others sexually transmitted infection (PATH, 2000). HPV is generally asymptomatic and easily transmitted. The virus can remain infection for years to estimate the degree to which standard STI prevention methods can affect the overall incidence of cervical cancer(PATH, 2001)

\subsubsection{Screening service as a preventive options for cervical cancer}

Screening is a means of accomplishing early detection of a disease in asymptomatic people (Akinremi, 2004). It involves the application of relatively simple inexpensive test to a large number of asymptomatic people in order to classify them as likely or unlikely to have the disease of interest (sankaranyan et.al, 2005). Screen positive person are then subjected to further investigate and or treatment procedure (Sankaranyan et.al, 2005). In the case of cervical cancer, it involves testing for the presence of cancer before there are many symptoms of finding on examination (Rich, 2002). Cervical cancer takes many years to develop and change can be detected in the cervix for some time before the appearance of cancer (WHO, 2004). When cancer is detected early, treatment is more effective and prognosis is better (Rich 2002, Blackman et al. 1999, Cesar et. al 2003). Cervical cancer is the first malignancy for which population screening has been demonstrates to significantly reduce the mortality due to it (Castronova, 1998). Regular cytological screening for cervical cancer reduces both the mortality and incidence of cervical of carcinoma in the screened population (ASC, 2002). Case control studies have established the effectiveness of screening in the control of cancer of the uterine cervix (Akinremi, 2004). Population studies have also show that country with formal screening programs and wide population coverage experience substantial drops in incidence and mortality. On the other hand neighboring countries with limited population screening did not experience this (Hakanma et.al, 1999).

\subsubsection{Screening practices among women}

Despite the several advantage of screening, it has been observed that screening is still generally poor especially in developing countries (Akinremi, 2004). This is one reason why about $80 \%$ of the 466,000 new cases occurring annually are found in developing countries (PATH, 2000). Screening rate in developing countries is still generally as low $5 \%$ although there are variations in different countries and among different groups of people (Akinremi, 2004). Cervical cancer screening (Cytology based mainly) is practices opportunistically in Nigeria. As in most developing countries, the concept of screening for cancer and it preemptive treatment is under developed (Thomas et.al 2005). In places where it is practiced, the practice is most often linked with family planning and antenatal practices. Sometime it is practices in an adhoc manner on symptomatic patients and a few who request for it. Sometime small- scale screening programs are also organized (Akinremi, 2000). The ideal ages for screening should then be $30-40$ years, which is the age when women are at the highest risk of precancerous lesions. However, younger women who have been sexually active should be screened as they might have lesions and even cancer especially if they have HIV infection. In a study $76.8 \%$ of patients with squamous cervical carcinoma - a cancer which is theoretically preventable by cervical cytology screening - had not received a smear test for 10 years or longer.

This observation strongly suggests that non-attendance to routine cervical screening is a major risk factor for the development of squamous cervical carcinoma. Non attendance to screening occurred in all age-groups some common reasons for not attending screening 
South American Journal of Public Health

Special Edition May 2016

included patients being unaware of the need for screening, the absence of symptoms, patients not knowing where to go to, and time constraints. When we talk of health care, we think of hospitals and drugs, but when we talk of preventive health- we should consider the issue of access. Screening services must be near enough to those at high risk, with little or no transportation cost to them. Remember at least $70 \%$ of Nigerians earn less than US $\$ 1$ per day. The most cost-effective strategies were those that requiredthe fewest visits, resulting in improved follow-up testing and treatment. Screening women once in their lifetime, at age 35, with a one- or two-visit screening strategy involving visual inspection of the cervix with acetic acid or DNA testing for human papillomavirus (HPV) in cervical cell samples, reduced the lifetime risk of cancer by approximately 25 - 36\%, and cost less than $\$ 500$ per year of life saved. Relative cancer risk declined by an additional $40 \%$ with two screenings (at ages 35 and 40), resulting in a cost per year of life saved that was less than each country's per capita gross domestic product - a very cost-effective result, according to the Commission on Macroeconomics and Health

\subsubsection{Factors influencing cervical screening behavior}

The major factor that affect the attitude and practice of women as regards cervical cancer and cervical screening can be grouped either as personal/individual factors and health care provider factors.

\section{a) Lack of knowledge and information on cervical cancer:}

Studies have shown that in many areas where screening behavior is poor there is generally poor disease knowledge among the people. Many women today still lack adequate knowledge about cervical cancer and the purpose of screening. In a study carried out among 38 Southeast Asia women living in the united state, $71 \%$ of women in the study did not know what cancer was (Phipps, Cohen, Sorn, Bratman, 1999). Also 74\% were unable to identify a cancer prevention strategy (Phipps et.al, 1999). A study carried out to assess Korean- American women's knowledge about cervical cancer using group discussion revealed that there was misinformation and lack of knowledge about cervical cancer (Lee, 2000). Similarly in Nigeria, the national HIV/AIDS and reproductive health survey (NARHS 2003)revealed that only $12.8 \%$ of women and $4.3 \%$ of men have ever heard about cancer of the womb. Also in Nigeria, a cross sectional study was carried out among women attending outpatient clinic and their accompanying persons. The study showed that only $15 \%$ of them the disease however appear to increase with increasing education(Daramola, 2001), in her study of the awareness of screening producer of carcinoma of the cervix smear amongst health service user in Lagos, Nigeria found that only $26.2 \%$ of them were aware of cervical cancer. Of these, only $29 \%$ knew it was possible to detect cervical cancer early. Almost a fifth (16\%)was aware of Pap smear and half of these got the definition right. In another study carried out in Maiduguri, less than $10 \%$ of the women were aware of the disease or the symptoms (Audu, El- Nafaty, Khalil and Otubu, 1999).

b) Socio- Economic Factor:

Educational qualification, financial status, social class, marital status and other socioeconomic education can all influence screening behavior. In both developed and developing countries women of low socio- economic status have a higher than average risk of cervical women of low socio- economic status have a higher than average risk of cervical cancer. Also they have a lower than average participation in Pap smear screening (Segnan, 1997). In Rome (Boinelli et.al, 1996)carried out a study in two town to find out the impact of education on cervical cancer a prerequisite for screening was associated with high level of education. Another study of Vietnamese and Caribbean women revealed that knowledge about cancer and identification of preventive measure was associated with employment outside the home, more years'o education and age (Philips et.al 1999). In southern Brazil, the risk factors most colour, young age low family income low schooling living alone and first childbirth after 25 years of age (Cesar, Horta, Gomes, Houlthusen, willrisch Kaercher, Lastrenski, 2003). Social class also has an influence on screening behavior. Generally women in lower social class tend 
to have lower screening participation rate than those in higher classes (Segan, 1999). In a study Aberdeen, screening status was also related to social class and education (Nicolle et.al 1991). In contract to this general observation (Clarke et.al 1998) observed that first nation women Colombia have less regular and frequent participation in screening programs. This is probably because they have more difficulty in obtaining culturally suitable health care service from respectful and consistent professionals.

\section{c) Urban and Rural Distribution}

The national reproductive health survey in Nigeria $(N A R H S, 2004)$ revealed than higher percentage (8.3\%) of urban dweller knew about uterine cancer compared with 7.3 of rural dweller(Katz 1998), in a conducted in Canada also reported that minority, rural, low income and older women face important barrier to screening. In the United State, unscreened population has usually included women residing in rural areas (Brown, 1996). This is probably due to the fact that rural women have poorer access to information and screening services.

\section{d) Psychological Barriers}

A number of studies have shown that one predominant reason why women are reluctant to go for screening is fear and anxiety. Many women believe that Pap smear is a test for cancer and fear positive result (Mckie 1993, Neilson and Jones et.al, 1998).cities a study in which women believed that receipt of an invitation to attend a smear indicated that their doctor knew they had cancer. Others fear harbored included fear of embarrassment (Fylan, 1998). Lee's study in 2000 among Korean American women revealed that psychosocial barrier such as fear; denial and confusion thinking were hindrance to screening. In Nigeria however, the percentage of family physician that offer cervical screening service is rather low. In a study carried out among family physicians from different geopolitical health zones in Nigeria, it was discovered that only $5 \%$ of the family physicians offered screening service for cervical cancer (Ajayi and Adewole 2002)

\subsubsection{Human papiloma virus vaccinations as a primary prevention}

The cervical cancer vaccine (Gardasil) is the first vaccine approved by the Food and Drug Administration (FDA) designed to prevent a cancer. This breakthrough led to the possibility that some cervical cancers could be preventable by vaccination (McIntyre P.2005, Lowndes CM, and Gill OM, 2005). The vaccine is recommended for girls 'ages 11 to 12 , although it may be used in girls as young as age 9. This allows a girl's immune system to be activated before she's likely to encounter HPV. Vaccinating at this age also allows for the highest antibody levels the higher the antibody levels, the greater the protection. The vaccine is given as a series of three injections over a six-month period. The second dose is given two months after the first dose, followed four months later by the third dose. Experts at the Centers for Disease Control and Prevention (CDC)recommend a catch-up immunization for girls and women ages 13 to 26 who haven't been vaccinated or who haven't completed the full vaccine series. By vaccinating this catch-up group, as well as the younger girls, we'll see the positive effects of the cervical cancer vaccine that much sooner. A more promising approach to primary prevention is vaccination against HPV (Kols and Sherris, 2000). In June 2006, the US Advisory committee on immunization practice (ACIP) voted to recommend the first vaccine developed to prevent cervical cancer and other disease in female caused by certain types of genital human papillomavirus (HPV). The vaccine developed to prevent cervical cancer and other disease in female caused by certain type of genital human papiloma virus (HPV). The vaccine, Gardasil manufacture by Merck and Co Inc. is based on laboratory research and technology developed at the national cancer institute (NCI). It protect against four HPV types, which together cause $70 \%$ of cervical cancer and $90 \%$ of genital warts (CDC, 2006, NCI, 2007).

The United State food and drug administration (FDA)recently licensed this vaccine for use in girls /women age $9-26$ years. The vaccine is given through a series of three shots over a six month period. The HPV vaccine is recommended for $11-16$ years old girls, and can 
South American Journal of Public Health

Special Edition May 2016

given to girls as young as 9 . The vaccine is also recommended for 13-26 years old girl/women who have not yet received or completed the vaccine series ideally, female should get the vaccine before they are sexually active. This is because the vaccine is most effective in girls/women who have not yet acquired any of the four HPV type covered by the vaccine. Girls/women who have not been infected with any of those four HPV types will get full benefit of the vaccine (CDC, 2006). Vaccinating at this age also allows for the highest antibody levels. The higher the antibody levels the greater the protection. The vaccine is given as a series of three injections over a six month period. The second dose is given two months after the first dose, followed four months later by the third dose. Experts at the Centers for Disease Control and Prevention (CDC) recommend a catch-up immunization for girls and women ages 13 to 26 who haven't been vaccinated or who haven't completed the full vaccine series. By vaccinating this catch-up group, as well as the younger girls, we'll see the positive effects of the cervical cancer vaccine that much sooner. The cervical cancer vaccine has proved to be remarkably safe. Over 16 million doses have been distributed in the U. S. The most common complaint is soreness at the injection site, the upper arm. Low-grade fever or flu-like symptoms also are common. Sometimes dizziness or fainting occurs after the injection, especially in adolescents. Overall, the effects are usually mild. However, some serious side effects have been reported, including a severe allergic response (anaphylaxis);neurological conditions, such as paralysis, weakness and brain swelling; and death. The FDA continues to monitor all such reports. To date, almost all reports of such adverse side effects appear to have occurred around the time of vaccination by chance. They don't appear to be caused by the vaccination itself. Monitoring is ongoing with this vaccine, as with all newer vaccines. Women and girls should remain seated in the clinic where they receive the vaccine for 15 minutes after the injection to reduce the risks of fainting or of an allergic reaction

\subsubsection{The role of health education and promotion in cervical cancer prevention}

Health education has been defined as any combination of learning experience designed to facilitate voluntary action conducive to health (Wass, 1995). It involves teaching individual families and communities what to do be healthy and avoid illness. It is designed to enable people change their attitude and behaviors and adopt better health habits. It aims to present health teaching in an attractive and acceptable ways to assist individual and communities take responsibility for their own health as well encourage people to utilize curative service (Bradley, 1978). The focus of health education is on behavior because health status is often as a result of behavior. Behavior often occurs as result of several factors, prominent among which is the availability of correct information which, in the context of reproductive health generally and cervical cancer in particular, guide individual and families on what to do to enhance reproductive that increase the risk of cervical cancer and encouraging regular screening and other behaviors that help protect against cervical cancer. Health promotion on the others hand entails the empowerment of the community in improving it health through education, provision of preventive service through addressing the social, physical ad economic environment (Moronkola, 2002). Several studies and program example have demonstrated the importance of health education and health promotion in improving reproductive health and preventing cervical cancer different group of people. In North Carolina, A five year program was conducted by the North Carolina Native American cervical cancer prevention project to evaluation the effect of health education increasing cancer Native American women in North Carolina. It was observed that women who received health education were more likely to have reported had a pap smear within the past year than women who did not received health education (Dagnan et.al 1996). Participatory qualitative research methods such as focus group discussion, in-depth interview, community mapping with women of various age group and their partners are important used in health education which are useful in providing insight into their needs and concern (PATH 2000). When 
adequate and accurate baseline information is obtained, the need of people in terms of precise information and easy access can be met more effectively.

\subsubsection{Knowledge and Perception of Cervical cancer and uptake of HPV vaccination}

The newly developed HPV vaccine by two separate drug companies: Merck, which produces Gardasil, and GlaxoSmith K line, which produces Cervarix (Koutsky L A, Ault K A 2002). Both drugs have undergone phase III trials, and was approved for use in the USA in 2006, the Merck vaccine was also approved for use in the UK in 2006(McIntyre P 2005, Koutsky LA, Ault KA 2002). To maximize effectiveness, the vaccine needs to be given to girls before they are sexually active. Determining the age of vaccination depend on the government policy in the different countries, In the UK vaccination programme suggested targeting girls aged 10- 12 years while the Department of Health (England) announced the Government immunization programme for HPV vaccination with the vaccination age as girls aged 12- 13 years (Harper DM, Franco EL 2002). Despite HPV vaccination being a relatively new concept, there are a number of studies that have discussed the effectiveness of the vaccine and how it works (Koutsky LA, Ault KA 2002 Coombes R 2007) (Harper DM, Franco EL 2002). However, relatively few investigations have addressed the public's support for vaccinating school age children. The majority of the research that has been undertaken has not been based in the UK (Harper DM, Franco EL 2002) and reports parental (especially maternal) and adolescent attitudes towards HPV vaccination, rather than the attitudes of the general public (Harper DM, Franco EL 2002). The attitude of mothers towards the HPV vaccine in the countries were they have be given was reported generally good, as most mothers took their daughters for vaccination in those counties (Harper DM, Franco El, 2002). A Canadian study, published in 2000, assessing public knowledge reported that only $13 \%$ of adolescents had heard about HPV (Dell DL, Chen H 2000), however a more recent study, conducted 2006- 2007, reported that $70 \%$ of respondents with female children intended to have their daughters vaccinated (Ogilvie GS, Remple V P, 2008). A study, in Georgia, undertook 35 focus groups with stratification by gender, race and location. Knowledge, attitude and beliefs about HPV were explored. Low knowledge and the association of the vaccine with STD were concluded to be barriers to future acceptance of the vaccine (Friedman Al., Shepeard H., 2007).

The relatively small number of UK based studies undertaken to date also tend to report that people generally know little about HPV, but after the provision of information, most support the introduction of the vaccine(Marlow LAV, Waller J 2007 -Brabin L, Roberts SA, 2006). A recent survey of British women aged 16-97 used an open questionnaire to elicit the causes of cervical cancer; only 2.5\% mentioned HPV and 7\% mentioned an unspecified sexually transmitted virus/infection (Brabin L, Roberts SA, 2006). However, the majority of parents of 11 - 12 year old school children state that they would allow their child to be vaccinated(Marlow LAV, Waller J, 2007, Brabin L, Roberts SA, 2007)and only a minority express concern that it may encourage unsafe sexual behavior(Marlow LAV, Waller J 2007, Brabin L, Roberts SA, 2006). Study in Nigeria also show 53\% level of awareness and uptake of cervical screening in Owerri, South Eastern part of Nigeria. Level of awareness is low, only about $15 \%$ of women aged $20-65$ yrs in the same region had heard about the disease. Prophylactic vaccines against human papillomavirus (HPV) types causing cervical cancer will soon be available Nigeria. Success of the vaccine relies on parents 'willingness to vaccinate their prepubescent daughters. Although a human papillomavirus (HPV)vaccine has been available for more than 3 years, little research has documented the uptake and predictors of vaccination among older adolescents and young adult women (Megan E. Roberts, 2010). In a study conducted in the UK, it was observed that mother's approval of HPV vaccination, mother-daughter communication about sex, and daughter's perceptions of vulnerability to HPV were positively associated with vaccination status (Megan E. Roberts 2010). From the research it was discovered that although many of these young women were old enough to receive the vaccine without their parents' consent, perception of their mother's approval and 
South American Journal of Public Health

Special Edition May 2016

mother-daughter communication about sex were important predictors of vaccination (Megan E. Roberts 2010).

\subsubsection{Concerns around the use of HPV vaccination}

The good news about cervical cancer is the increasing evidence now available in the literature which indicates that a vaccine directed against the human papillomavirus (causative agent of cervical cancer)can reduce the incidence of cervical pre-lesions that lead to cervical cancer. In October 2005, Merck \& Co., Inc. announced the results of its phase III trial on its vaccine, Gardasil. The study which enrolled over 12000 women in 13 countries, demonstrated the nearly $100 \%$ prevention of non-invasive cervical cancers in women who received the vaccine. Similarly, GlaxoSmithKline’s Cervarix is undergoing Phase III trials, and has so far produced impressive reports. The vaccine is now licensed in more than 45 countries for use in 9 to 26 year old girls. Nevertheless, both vaccines hold exciting new promise for the development of highly effective primary prevention strategies for cervical cancer. There can be no doubt that the HPV vaccine will be extremely relevant for many African countries (since women have limited access to Pap smear), but many questions need to be answered to clarify its usefulness and potential effects in Africa.

But some of concerns observed are in the first place, the HPV vaccine was developed against HPV 16 and HPV 18 serotypes, the two most frequent causes of cervical cancer. However, it is not known whether the vaccine has equal efficacy against cervical cancer due to other sub-types of HPV. Thus, each country needs to identify the HPV sero-type most prevalent in its territory in order to determine the effective and relative effectiveness of the available HPV candidate vaccines. Secondly, it is not yet clear whether the advent of the vaccine would obviate the need for secondary prevention of cervical cancer using Pap smear and other screening procedures. To date, these secondary prevention measures have been slow to scale up in many African countries, and it is possible that the introduction of the HPV vaccine will further subsume these secondary efforts. However, in view of the increasing use of cheaper and more cost-effective methods such as visual inspection of the cervix, it is evident that secondary prevention methods will continue to be promoted in many African countries. A third problem with the use of the HPV vaccine is the high cost of the vaccine. African countries, confronted by several contending health problems may feel unable to afford the current high cost of the vaccines. Thus, special considerations need to be put in place to ensure that the vaccine is made affordable and accessible to African women. In particular, pharmaceutical companies need to develop a special pricing mechanism for poor countries; and donor agencies ought to recognize the importance of this vaccine for the promotion of women's health in Africa and therefore provide substantive support for African women. As a major hurdle will be the price of the vaccine. Merck has said that the list price of the vaccine will be $\$ 360$ for the three doses, making it one of the most expensive vaccines in the market. In the developed countries, private insurance companies usually cover ACIP recommended vaccines, so most insured individuals will likely have coverage, although it is still too soon to tell for now. The Vaccines for Children program, a federal entitlement program, covers the cost for children under age 19 who are uninsured or underinsured, on Medicaid, Alaska Natives, or American Indians(Morris M, Tortollero-Luna G 2001). However, for women 19 and older, the policies are different. Under Medicaid — the primary form of coverage for low-income women - vaccines are considered an "optional" benefit, which means that each state decides whether or not it will be a covered service. Some states also have public health programs in place that provide free or low-cost vaccines to those whose health insurance plan does not cover vaccines (Armstrong C. 2007)For uninsured women, Merck has announced that it will establish an assistance program to provide free vaccines, including Gardasil, to uninsured and low-income adults ages 19 and older who visit private practices that already provide Merck vaccines. Many uninsured women in this age group rely on publicly funded clinics and health centers, not physicians in private practice. 


\subsubsection{Acceptability and attitude around the use of HPV vaccine}

Numerous studies have evaluated acceptability and attitudes regarding the use of the HPV vaccine. Acceptability among gynecologists and physicians is generally high, depending on factors such as a patient's gender, age, and sexual history, as well as efficacy of the vaccine (Chirenje M. Z, 2001). A review of research regarding STI and HPV vaccine acceptability also indicates that health care providers and professional health organizations play a large part in a parent's decision to vaccinate their daughters. Parents are more likely to follow the recommendations and information put forth by health care providers, and health care providers are more apt to follow a professional health organization's endorsement of a vaccine (Leroy V, Ladner J, 1999). Thus, health care providers will likely play a pivotal role in relaying information about HPV and HPV vaccination in a manner to ensure the targeted population is vaccinated. The approval of the new vaccine holds great promise for millions of women. Not only can it greatly reduce deaths attributable to cervical cancer, but it also has the potential to reduce the economic and emotional burdens that women experience when they are faced with an abnormal Pap smear that requires further testing and treatment. The key to the success of this new vaccine will be in how policymakers, health care providers, parents, and women and girls respond to make sure that all those who can benefit from this new technology have access to it. Thus a small, inexpensive intervention such as cervical screening and HPV vaccination could potentially save numerous lives. It is estimated that screening in the United Kingdom saves 5,000 lives per year and in Europe 4,500 lives per year (GCF). Over $95 \%$ of patients with early cancer of the cervix can be cured adequate (Stjernsward J, Eddy D, Luthra U and Stanley K. World Health Forum 1987;8: 42-45). In Africa, there can be no doubt that African countries need to embrace the new vaccines for the prevention of cervical cancer. Experience has shown that new vaccines have taken up to 30 years to gain grounds in African countries, mainly because of paucity of the relevant information. To date, several lifesaving vaccines including the polio vaccines are still poorly accepted in some parts of Africa. To avert this scenario for HPV vaccines, African countries must begin to develop strategies for the introduction of the vaccines in their territories. In this respect, it is noteworthy that a global call to stop cervical cancer was recently launched in London, UK, which called on governments to prioritize cervical cancer in their national development and health programs. Following this, the Princess Nikky Foundation, an NGO in Nigeria organized a highly successful conference in Abuja, Nigeria 7 in July 2007, involving several participants from all of Africa, where information was provided on cervical cancer and the new initiatives, such as the HPV vaccines necessary to reduce the disease burden. These kinds of initiatives are extremely necessary to generate awareness of cervical cancer in Africa and the benefits of primary and secondary prevention interventions to reduce the disease incidence. We believe that African countries can take appropriate steps to promote the use of HPV vaccines and initiate cervical screening procedures to prevent cervical cancer in the next generation of women.

\subsubsection{Conceptual framework}

The conceptual frameworks that are will be adopted for this research is the health belief model. The Health Belief Model (HBM) is credited to a group of U.S Public Health Service social psychologists (U. S. Department of Health and Human Services, 2005). It is useful for predicting the likelihood of taking preventive health actions. The HBM stresses the factors that govern the uptake of preventive health behaviors and in this case it is the uptake of HPV vaccine. The HBM has several components, these include: Modifying factors, perceived susceptibility, perceived severity, perceived benefits, cues to action and self efficacy. These inform the selection of the variable to be study in the research.

- Modifying Factors- These are demographic characteristics such as, gender, age and level of education and other factors such as knowledge of cervical cancer and HPV vaccine as this that might likely influence the uptake of cervical cancer vaccine 
- Perceived Susceptibility- This is the belief of mothers about the chances of their adolescent girls being exposed to risk of be infected with HPV which lead to cervical cancer and the adolescent girls also perceived themselves also susceptible HPV which lead to cervical cancer. If the belief of mothers and daughter is high there is likelihood that they what to take the vaccine.

- Perceived severity- The belief of mothers about the seriousness of the health effects of cervical cancer will greatly influence the involvement in the uptake of vaccine. If the condition is perceived serious by mothers and adolescent girls themselves they will be more willing to be involved.

- Perceived benefits- This is the perception of mothers and the adolescent girls about the benefits of HPV vaccine in limiting the exposure of adolescent girls to cervical cancer is high they will be more likely to be involved uptake of the vaccine.

- Perceived barriers: These refer to factors that might impede the uptake and acceptability of HPV vaccine. These factors include previous bad experience from others forms of immunization and vaccine use. The channel and methods of information dissemination on the prevention methods and may be cost of the vaccine.

- Self efficacy: This measures the adolescent girls and mothers level of confidence to access service and information on cervical cancer and the uptake of the vaccine

The tenets of this model will be helpful in determining perception of vulnerability and severity of adolescent girls to cervical cancer and characteristics like age, knowledge, gender and educational qualification of parents that will influence their uptake of HPV vaccine. It will also be helpful in determining perceived barriers to the uptake of HPV vaccine for instance past experiences of immunization services and lastly their sources of information about cervical cancer. The details of the application of the model are presented in figure below 38

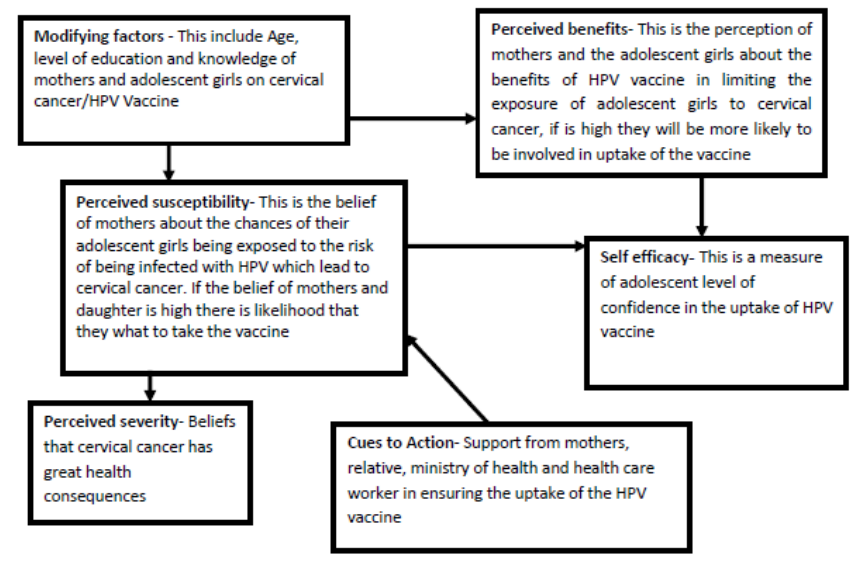

Figure 1 Source: National Institute of Health and Human service. Concept adapted from the national institute of health (2005)theory at a glance: A guild for health promotion practice.

\section{Methodology}

\subsection{Research design:}

This study is descriptive and cross sectional studies. It was designed to assess and document mothers and their Adolescents daughters' attitude and willingness to adopt human papilloma virus vaccine in Akinyele Local Government Area toward the uptake of HPV vaccine. It also sought to understand the best communication strategy that will be employ in disseminate HPV vaccine.

\subsection{Independent and dependant variable}

The variables of interest for this research are attitude toward vaccination of HPV vaccine, willingness to adopt the vaccine, knowledge on HPV vaccine and the influence of previous 
immunization experience. The independent variables in the study include the socio demographic data which include the age, marital status, parity and ethnic group. The dependent variable on the other include: attitude toward HPV vaccine, willingness to adopt HPV vaccine and previous immunization experience

\subsection{Description of study location/site}

This study was carried out in Akinyele LGA;Akinyele Local Government Area was created in 1976 with the Administrative Headquarters located at Moniya. The Local Government shares boundaries with Afijio Local Government to the north, Lagelu Local Government Area to the east, Ido Local Government Area to the west and Ibadan North Local Government Area to the south. It occupies a land area of 464.892 square kilometers with a population density of 516 persons per square kilometer. The local government is 575 square kilometer in area and lie within latitude 3 and 55 and longitude $732 \mathrm{~N}$ and $737 \mathrm{~N}$ of Ibadan. U sing 3.2\% growth rate from 2006 census figures, the 2010 estimated population for the Local Government is 239,745(National Population Commission Ibadan 2010) with 105, 594 male and 134,151 female.

Akinyele LGA has in all 12 political wards dominated by the Yoruba's among other resident tribes like Ibo, Hausa, Fulani, Nupe and $\mathrm{T}$ iv reside there. There were about twenty secondary schools, ninety - two primary schools and thirty - nine private nursery and primary schools, scattered in the local government (Adegbite, 1994). They are predominate religious are Christianity, Islamic and Traditional religion background. Also of the population in Akinyele $90 \%$ is involved in agriculture as a primary source of income while others are petty trader and civil servant. The rainy season falls between late April and October, while dry season start in November and ends in March. The main streams are Ose, Ona and Odo ona. There is a large forest reserve at Atan imini near Ijaiye, in the southern part the local government area and a derived savannah in the north. The area is endowed with fertile agricultural land suitable for the cultivation of fruits like orange, mango, banana, and pineapple. Common health problem among the women are malaria and common cold. Generally they use health facilities for maternal and child health service but often times they their babies at home. They have a strong belief in the ability of God to keep them healthy. Politically, the local government is subdived into 12 wards. However, for the purpose of health management it is subdivided into 15 health districts (Oluwatosun. O. A 2005)

\subsection{Study design and scope}

The study design for this research is descriptive cross - sectional survey designed to determine Mothers and their Adolescent daughters 'attitude and willingness to adopt HPV vaccine

\subsection{Study population}

Target population considered for the study are adolescent young girls between $10-14$ and their biological mothers in Akinyele LGA. They are selected for this research because they are important population that should be consider for the HPV vaccines program as the adolescent girls will be the direct beneficial of the vaccine and mother are also major stakeholder in vaccination program in Nigeria (Oladokun R . 2008). The adolescent girl was selected because they have a high risk of cervical cancers infection due to their to early sexual initiation and unprotected sexual intercourse (Dell DL, et .al 2000) which has been linked with Human Papiloma Virus as the causative agent for cervical cancers (Akinremi, 2005). The vaccine developed is most effective for adolescent girls between (10 - 16 year)(Olshen E, et .al 2004). Also since they are going to being benefiting from the vaccine their opinion and intention to take is important. The experience of mothers from previous immunization vaccination will also go a long way in influencing the decision to take the HPV vaccine or not. 
South American Journal of Public Health

Special Edition May 2016

\subsection{Sample size determination}

Sample size $n=\left[\mathbf{D E F F}^{*} \mathbf{N p}(\mathbf{1 - p})\right] /\left[\left(\mathbf{d}^{2} / \mathbf{Z}^{\mathbf{2}} \mathbf{1 - \alpha} / 2^{*}(\mathbf{N}-\mathbf{1})+\mathbf{p} *(\mathbf{1}-\mathbf{p})\right]\right.$

Where;N: Population Size (No of mothers in the LGA): 134,151 P: Hypothesized frequency of outcome factor in a population or reasonable estimate of key proportion $50 \%+$ /-5 In this study, key proportion refers to the proportion of mothers who have daughter (10 14 years)confidence limit as \% of 100 (absolute +/_ \%): 95\% Design effect (for cluster surveys-DEFF)N = 250 at 95\% confidence level. The calculated sample was however increased to 320 in order to address any possible cases of attrition or incomplete response.

\subsection{Sampling procedure}

In order to obtain a sample of the population for the study, a multi stage random sample technique was adopted. The procedure involved different stages which include;

Stage 1 The LGA was classified based on the political ward; Akinyele Local Government Area has a total of 12 political wards. $50 \%$ of the 12 ward was selected to show representativeness and generalization of data for the Local Government Area. So a total of six wards out of the Twelve political wards were randomly selected using the simple random sampling. The following wards was selected; Arulogun, Moniya, Iwokoto/Amosun, Ojoo/Ajibode, Akinyele and Iroko. Then from each of the selected ward above one community was randomly selected from each of the ward bring it to a total of 6 communities

\begin{tabular}{|l|l|l|l|}
\hline WARD & COMMUNITY & TOTAL POPULATION & SAMPLE SIZE \\
\hline Arulogun & Shagbe & 687 & 20 \\
\hline Moniya & Akingbile & 578 & 15 \\
\hline Iwokoto/Amosun & Orugun & 3882 & 80 \\
\hline Ojoo/Ajibode & Sasa & 9225 & 170 \\
\hline Iroko & Disyosa & 354 & 20 \\
\hline Akinyele & Akinyele & 592 & 15 \\
\hline & & & 320 \\
\hline
\end{tabular}

Figure 4: Source; National Population Council Oyo State; 2008 projection

Stage 2 Then each community has an allotted sample size based on the total percentage using proportionate sampling. Then households were systematically selected with an interval of 3 household from the centrally located point in the community. In all, a total of 160 mothers and 160 daughters were sampled.

Stage 3 Then household was systematically identified with the class interval of three from the communities in each of the ward, the household were the interview was conducted was such that have mother who has a female adolescent between the ages of $10-14$ years. Then semi structure questionnaire was administered to both mother and the female adolescent in the same household. The total sample size was determined using the EPI INFO Statistical package. The Calculated sample size was 250 but will be jack up to 320 for attrition and incomplete response.

\subsection{Instruments for data collection}

The main instrument used for data collection is this study is the Semi structure questionnaire supported prior to the development of the Semi structure questionnaire. Focus group discussion was conducted to help formulate the nature and phrasing of the questions in the Semi structure questionnaire.

\subsubsection{Focus Group Discussion (FGD)}

An approved guided discussion format pretested at Yemetu in Ibadan North Local government area of Oyo state among mothers was used for illicit information from mothers in Akinyele Local government. After the protocol of obtaining permission, meeting with bale and bales, women leader and women of the community in general, appropriate date and time 
were fixed for the Focus group discussion in the selected communities. We had a total of 6 FGDs across the six communities with one in each community. After the general meeting with the women, participants for the focus group discussion were selected. The moderator, the recorder and observers was selected to conduct the Focus group discussion. The researcher served as an observers and the role of the observer was to note the non verbal expression of the participants. With the permission of the participant in each of the sessions, the whole programme from introduction to the end was tape recorded on audio tape. The group discussion was done in the local language (Yoruba). The focus group discussion was held among mothers who have adolescent girls between $10-14$ years and live in Akinyele LGA. The characteristic of mothers who were involved in FGDs were; 30 - 40 years of age and had daughter (10 - 14 years). They had primary school and below in their educational qualification. At the end of each session, there were conference in which observation during the session were raised and discussed. The moderator and the recorder later transcribed the tape while, the researcher (who analyzed the data)rechecked them.

\subsubsection{Semi structure questionnaire}

The main instrument used for data collection in this study was the semi structure questionnaire to be supported by the Focused Group Discussion. The decision to use semi structure questionnaire as the main instrument for data collection was based on the finding from the use of questionnaire during the pre test as it generate much data and good response because they could compare their experience with previous vaccination taken in the past. But the response from Focused Group Discussion was also key and vital because HPV vaccine was a new vaccine.

For the semi structure questionnaire each of the research assistant was assigned an alphabet to identify data collection by each individual. This helped to monitor each data collector and provided opportunity for necessary guidance. The details of data collection procedure were discussed with community heads and leaders. The semi structure questionnaire was administered to young adolescent $(10-14)$ and their mothers to determine the attitude and perception of vulnerability to cervical cancer, willingness to adopt the vaccine for prevention, previous immunization experience. It also assessed the implementation and challenges facing from previous immunization prevention programs. The semi structure questionnaire had in all six (6) sections which include; demographic data, previous immunization experience, knowledge and awareness, willingness toward the uptake of HPV vaccine, attitude toward the uptake of HPV vaccine, and best communication strategy in disseminating HPV vaccination message.

\subsection{Validity and reliability}

According to Davitz and Davits (1997), validity is the extent to which an instrument actually measure what is purports to measure while reliability is the degree to which an instrument yields constant responses. To ensure these, the researcher did an extensive literature search on previous study on cervical cancer and HPV vaccination. Finding from this search were employed in the design of the data collection instrument used. The instrument was presented to expert like medical sociologist psychologist, medical statisticians and health education specialist to check for face and content validity. Pre testing of the questionnaire was done a Yemetu in Ibadan LGA which is similar to my research site for useful criticisms and suggestions. Also in ensuring validity of the instrument training of research assistant was done and pretesting was also done among the research assistant to ensure uniformity of ideal and proper use of the technically concept. To ensure the reliability of the instrument semi structure questionnaire was administered on $10 \%$ equivalent of the sample size with similar characterizes in Yemetu Ibadan North LGA. The Cronbach Alpha coefficient was used to confirm the reliability of the data and analysis of the pre test data was done using cronbach alpha correction of statistician's package for social science. Alpha cronbach is a model of internal consistency, based on the average. This was done to ascertain the psychometric 
South American Journal of Public Health

Special Edition May 2016

properties of the instrument. According to this approach, result showing correlation coefficient equal or greater than 0.05 is said to be reliable.

\subsection{Ethical consideration}

A formal ethical approval to carry out the research Mother and Their Adolescent daughters' Attitude and willingness to adopt of Human papilloma Virus vaccine in Akinyele Local Government Area of Ibadan was given from the Oyo state ethical Review Committee in the Oyo state secretariat Ibadan. Before the selection of the women for FGD, community heads know as bale and women leaders know as Iya lode were briefed about the study consents was obtained from them while corporate consent was also given by the women for the FGDs, while the mothers and the daughters sign the individual consent form for the semi structure questionnaire. Individual respondents also had explanation regarding the study, and the average time requires for semi structure questionnaire. Each respondent that felt they could not complete the questionnaire were given the freedom to discontinue. In all the six communities we had 16 participants that did not answer to some sections of the semi structure questionnaire.

\subsection{Data collection process}

Visit was made to all the selected communities in company of 6 researches assistant to familiarize them with the community and intimates them with the study objective prior to the interview. The semi structure questionnaire and FGDs was conducted by the researcher with the help of the trained assistant. The semi structure questionnaire was developed after review of literature. The semi structure questionnaire consist of six sections A, B, C, D, E and F. Section A focuses on demographic information, while section B consist of previous immunization experience. Section C consists of information on awareness and knowledge while section D contained information on willingness toward the uptake of HPV vaccine. E. measured the attitude toward the uptake of HPV vaccine. F focuses on communication strategy for the determination of cervical cancer information.

\subsection{Limitation of study}

Some of the limitation faced in the process was the low response and incomplete response by the adolescent girls due to their age and level of understanding. Although this study focused on very sensitive and personal issues which make it difficult at the initial stage for the research participant not willing to give all information needed either due to difficult in understanding the technical issues on HPV vaccine. For the adolescent girls it was an issue of their age and while for the mothers it was the low illiteracy level due their educational qualification. But effort was made to reduce this problem by assuring the participant that information given by them will be kept in confident and no name will be collected. Also the semi structure questionnaire was well simplified and translated into Yoruba language which facilitated easy understanding by the adolescent female and the low literacy mothers.

\section{Results}

\subsubsection{The demographic characteristic of the respondent $(N=320)$}

Demographic characteristic of respondents shown the mean age of the daughter as $13.24 \pm$ 1.55 while that of the mother was $35 \pm 5.89$, while majority $75 \%$ of the mothers are illiterate with no form of education; few others $10 \%$ have attended primary school education while $10 \%$ had secondary school and 5\% had NCE certificates respectively. Majority of the daughters are students; $75 \%$ of them are in secondary school with Junior Secondary School 3 having the highest frequency. While a few of the daughters, about $25 \%$ are in the primary schools. About $97 \%$ of mothers indicated that they are married and the remaining $3 \%$ didn't indicate their marital status. Majority of the mothers are petty traders in the community with commodities like fish selling, selling of provision, hairdressing and fashion designing. A few others are civil servants and clerical staff like typists, attendants and cleaners in various 
organizations. On the number of children ever had (parity)by the mothers $67 \%$ of the mothers have 5 children and above while 27\% of them have between 4 and 3 children and $6 \%$ have 2 children. The ethnic backgrounds showed that a majority of about $97 \%$ of the respondents are Yoruba with a few others tribes like Hausa and Igbo as 3\% .

Table 1.0 Socio- demographic distrubution of the respondents

\begin{tabular}{|l|l|}
\hline VARIABLE & $\begin{array}{l}\text { No (\%)N }=\mathbf{3 2 0} \\
\text { N0 (\%) Mother - 160 } \\
\text { N0 (\%) Daughter - 160 }\end{array}$ \\
\hline Age (Years) Mothers & \\
$30-40$ & $70 \%(112)$ \\
$40-50$ & $20 \%(32)$ \\
$>50$ & $10 \%(16)$ \\
Daughter & \\
$10-13$ & $86(138)$ \\
$14-16$ years & $14 \%(22)$ \\
\hline Religion & \\
Christianity & $58 \%(185)$ \\
Islam & $34 \%(108)$ \\
Others & $8 \%(27)$ \\
\hline Ethnic Group & \\
Yoruba & $97(155)$ \\
Igbo & $2 \%(3.2)$ \\
Hausa & $1 \%(2)$ \\
Others & - \\
\hline Level of education completed Mothers & $75 \%(120)$ \\
No formal education & $10 \%(16)$ \\
Primary school education & $10 \%(16)$ \\
Secondary school education & $5 \%(8)$ \\
Post secondary education & \\
\hline Daughter & - \\
No formal education & $75 \%(120)$ \\
Primary school education & $25 \%(40)$ \\
Secondary school education & - \\
Post secondary education & $15 \%(24)$ \\
\hline Occupation /Profession Mothers & $60 \%(96)$ \\
Civil servant & $20 \%(32)$ \\
Traders & $5 \%(8)$ \\
Farmers & $6 \%(10)$ \\
\hline Parity (mothers) & $27 \%(43)$ \\
$1-2$ children & $67 \%(107)$ \\
3 - 4 children & \\
5 children and above & \\
\hline
\end{tabular}

Table: 2. 0 Respondents awareness on cervical cancer, HPV virus and HPV vaccination

\begin{tabular}{|l|l|l|l|}
\hline S/N & VARIABLES & $\begin{array}{l}\text { Mothers } \\
\mathbf{N = 1 6 0 ( \% )}\end{array}$ & $\begin{array}{l}\text { Daughter } \\
\mathbf{N = 1 6 0 ( \% )}\end{array}$ \\
\hline 1 & Knowledge on cancer & $76(72 \%)$ & $46(28 \%)$ \\
\hline 2 & Information on cervical cancer & $35(21 \%)$ & $10(6 \%)$ \\
\hline 3 & Causes of Cervical cancer & $47(29 \%)$ & $24(15 \%)$ \\
\hline 4 & Symptoms of cervical cancer & $43(26 \%)$ & $15(9 \%)$ \\
\hline
\end{tabular}


South American Journal of Public Health

Special Edition May 2016

\begin{tabular}{|l|l|l|l|}
\hline 5 & Prevention of cervical cancer & $46(28 \%)$ & $10(6 \%)$ \\
\hline 6 & Causative agent of cervical cancer & $35(21 \%)$ & $15(9 \%)$ \\
\hline 7 & Knowledge Human Papiloma Virus & $38(23 \%)$ & $4(2 \%)$ \\
\hline 8 & HPV Vaccine & $38(23 \%)$ & $5(3 \%)$ \\
\hline 9 & $\begin{array}{l}\text { prevent the Cervical cancer virus THROUGH } \\
\text { HPV }\end{array}$ & $53(33 \%)$ & $20(12 \%)$ \\
\hline 10 & Aware of government vaccination plan & - & - \\
\hline 11 & $\begin{array}{l}\text { Adolescent girls need to be vaccinated with } \\
\text { HPV vaccine }\end{array}$ & $68(61 \%)$ & $23(14 \%)$ \\
\hline 12 & $\begin{array}{l}\text { Health care centers was the source of } \\
\text { information }\end{array}$ & $70(44 \%)$ \\
\hline 13 & $\begin{array}{l}\text { Social network was the source of information } \\
\text { Educational center was the source of } \\
\text { information }\end{array}$ & $34(21 \%)$ & $87(54 \%)$ \\
\hline
\end{tabular}

\subsubsection{Awareness of cervical cancer and the HPV vaccine}

The awareness level on cancer was generally high as the majority of the mothers heard of cancer before especially breast cancer. But specific knowledge on causes, symptoms, treatment and management of cancer was very low. Also awareness on cervical cancer was very low as Majority said they have not heard about it before nor way of preventing it like the use of pap smear were all very strange term to the mothers. The few of the mothers who said they have heard about cervical cancer before still have very level of knowledge on the prevention, causes, symptoms, treatment and management. But majority of the daughter did not respond to the question on knowledge and awareness as they said they do not have any form of awareness or knowledge on cancer or cervical cancer before. Only a few of the daughters, especially the older ones (14 - 16 years) testified to have heard about cancer in school. The main source of information for those who have heard about cervical cancer was the television and health care centers for the mothers and schools for daughters. Awareness on HPV vaccination was very low as majority of the respondents, both the mothers and daughters have not heard of HPV vaccine before. So the researcher had to explain the function of the HPV vaccine and its importance and inform them of the government's plan to give it to girls of ages $10-16$ years of age soon.

Table 3.0 Respondents reasons for taking previous immunzation

\begin{tabular}{|l|l|l|}
\hline S/N & VARIABLES & Mothers N=160(\%) \\
\hline 1 & Received vaccination for your daughter in the past & $120(75 \%)$ \\
\hline 2 & Everybody need to taken vaccine & $79(49 \%)$ \\
\hline 3 & Knowledge on important of vaccination & $134(84 \%)$ \\
\hline 4 & Vaccination help in maintaining good health & $145(91 \%)$ \\
\hline 5 & Vaccination of children is cost effective & $113(71 \%)$ \\
\hline 6 & Vaccination prevent disease & $148(93 \%)$ \\
\hline 7 & Any side effect from previous vaccine & $49(31 \%)$ \\
\hline 8 & Positive experience from previous vaccine & $89(56 \%)$ \\
\hline 9 & Negative experience from previous vaccine & $34(21 \%)$ \\
\hline 10 & Expectation meet in the last vaccine & $78(49 \%)$ \\
\hline 11 & Previous experience influence your future decision & $134(84 \%)$ \\
\hline 12 & Received information before the previous vaccination & $56(35 \%)$ \\
\hline 13 & Proper information important before vaccination & $121(75 \%)$ \\
\hline
\end{tabular}




\subsubsection{Experience from previous Immunization}

The importance of vaccine was an area where majority of the people have clear understanding and high level of awareness on. Majority of the mother and daughter believed that vaccination is important and should be encouraged when made available for any disease. Majority of women who were above 40 years and have daughters who were 14 - 16 years age agreed that vaccination reduced the burden of disease and it cost effective giving vaccine than treatment of any disease, vaccine help in proper development and growth of the child. 'I took all my seven children, both boys and girls for all the required immunization in the health care center and since then none of them came down with any serious sickness or disease", While a few other mothers whose daughters were much younger $(10-13$ years $)$ saw vaccination as mere routine practice that is expected of them by the government and those around them, they did not see themselves as vital in the decision to take the vaccine for themselves or for their children 'We have no option than to take our children for the immunization as the government said everybody much take it and because everybody around is taking it you would not want to be left out' It observed, that the daughter ( $10-13$ years) have low level of awareness on the important of vaccine even though they have taken vaccination in the past they cannot say categorically the important of vaccination. While those between $14-16$ years of age have some form of information on the important of vaccination as they say it safe guard the body against disease and infection. The reduced awareness on the important of vaccine among the daughters could be as a result of their age. Majority of the women and daughter agreed to have taken vaccination at some point in their life before. The vaccine were identified based the location of the body part were they received it and during which occasion. Some of the vaccines taken by the mothers themselves in the past include vaccine to prevent the following; Tetanus, Tuberculosis, Hepatitis and whooping cough which was given during antennal service. While vaccine received by their daughter include; Polio vaccine, BCG, DPT, vitamin A, Yellow fever, Meningitis and measles. A few of the daughter described their experience as painful during the process of getting the vaccine and was characterized by fever and running temperature after worth, but majority of the daughters think it was beneficiary and helpful as they got protection and sound health after worth. Few of the daughters said they were force to take the vaccine without their consent and opinion by their parent especially the mothers. But the views of mothers on their experience were not far from that of the daughter. Majority of the mothers described their experience as good and all they experienced after the vaccination was expected as the health worker informed them before they received it. Although majority of the daughter said they were given any information on the various vaccinations they took in the past. While few of the mothers emphasized the need to adequately provide relevant information on what is expected after any vaccination program to the beneficiary of that vaccine especially the mother "We need to be inform on the benefit, side effect, immediate reaction of the vaccine and long term impact and benefit when taking any vaccine, for example when a child take BCG after worth you may have running temperature which is expected but if the mother is not aware she can beginning to panic",

The views and opinions of both mothers and daughters about vaccination service includes the following; to make us healthy, prevent diseases, safe guard us from diseases, make us grow well and ensure proper development of children. Most of the personal experiences shared from previous immunization were positive; we have benefit so much from previous vaccine we have taken but the bad experiences was due to the lack of proper information about vaccine from the health workers . One of the participants narrated a friend story that had bad experience from vaccination. 'One of my family friend after receiving the childhood vaccination when the child was teething had the child developing fever, but instead of the mother taking the child to the clinic she gave the child local herbs(Agbo) the child's condition got worse and before they arrived the hospital the child gave up. The doctor then inferred that the local herb had reacted with the vaccine the child had earlier received" So this buttresses the need to give out proper information on the vaccination 
South American Journal of Public Health

Special Edition May 2016

especially side effect and body reaction after taking the vaccine and how it should be manage. Majority of the mothers didn't think their experiences in the past immunization will influence their decision negatively in taking the new HPV vaccine because it a different disease and its experience will be different. Also they think that cervical cancer is deadly so anything available to prevent it will be taken seriously. Majority of the daughters think the decision to take the vaccine will depend on their parent and not their previous experience as money might be involved and also health care decision are taken by their parent.

"Vaccination is use as a form of protection against diseases and infection and helps build the body immunity. Therefore it is important for anybody to take the vaccines that has been produced for specific diseases irrespective of sex, age and qualification" Majority of the women think that vaccination is important and should be encourage by all relevant stakeholder especially the HPV vaccine that can save the life of our younger generation of women from be infected with HPV virus which cause cervical cancer, that is very deadly. Mothers with older daughters think we cannot determine the sexual behavior of their daughters as many of them engage in pre marital sexual affairs and they have high sexual desire now so they are predisposed HPV which causes cervical cancer.

Table 4.0 Reasons for mothers intentions in allowing their daughter to take the vaccine

\begin{tabular}{|l|l|l|}
\hline S/N & VARIABLES & $\mathbf{N}=\mathbf{1 6 0}$ (\%) \\
\hline 1 & $\begin{array}{l}\text { Will consider the opinions of those around before allow my daughter take } \\
\text { the HPV vaccine }\end{array}$ & $34(22 \%)$ \\
\hline 2 & $\begin{array}{l}\text { Are you willing to allow your daughter }(10-16 \text { years)take the HPV } \\
\text { vaccine? }\end{array}$ & $150(94 \%)$ \\
\hline 3 & Negative Health effect of cervical cancer & $124(78 \%)$ \\
\hline 4 & All vaccination is important for good health & $89(56 \%)$ \\
\hline 5 & Girl health is important for national development & $86(53 \%)$ \\
\hline 6 & If the vaccine is given for free & $145(90 \%)$ \\
\hline 7 & If the safety and efficacy vaccine is know & $121(76 \%)$ \\
\hline 8 & Accessibility of the vaccine & $147(93 \%)$ \\
\hline
\end{tabular}

Table 5.0 Willingness to received the vaccine by the daughters

\begin{tabular}{|l|l|l|}
\hline Variable & $\begin{array}{l}\text { N=160 (\%) } \\
\text { YES }\end{array}$ & $\begin{array}{l}\text { N=160 (\%) } \\
\text { NO }\end{array}$ \\
\hline Will you take HPV vaccination when made available? & $133(83 \%)$ & $12(7 \%)$ \\
\hline Will you recommend your friend to take the HPV vaccine & $67(42 \%)$ & $40(25 \%)$ \\
\hline $\begin{array}{l}\text { Will your previous experiences in any of the immunizations } \\
\text { influence your decision to take the HPV vaccine }\end{array}$ & $14(9 \%)$ & $130(82)$ \\
\hline If your mother ask you to take the vaccine will you take & $154(96 \%)$ & - \\
\hline $\begin{array}{l}\text { If your mother disallowed you from taking the vaccine will you } \\
\text { take it }\end{array}$ & $16(10 \%)$ & $132(82 \%)$ \\
\hline
\end{tabular}

\subsubsection{Intention toward the uptake of the HPV vaccination}

High desires to take the vaccine were expressed by the daughter and by the mother to allow their daughter to take the vaccine when is made available. But the information on the importance of the vaccine and side effect (if any) should be made available to them. Issues around availability of the vaccine at the community level, affordability in terms of cost of the vaccine and accessibility of the vaccine in terms of the location were to receive came out as a strong factors that can affect uptake of the vaccine. Some of the concerns raised include the cost of the vaccine, the side effects of the vaccine and location of sites where the vaccines will be made available. Some of the mothers were of the opinion that if the government wants them to take the vaccines then they need to ensure that the vaccine are made available in the community not at the big hospitals in the city. The government will have to ensure the vaccine is made available for free due the poverty level in the country so everybody can have 
access to it. If it's made available, accessible and affordable we will ensure their daughters who are eligible to take the vaccine receive it so as to protect their life and save them from cervical cancer in future. Then they will not alone take their daughters to receive it but also ensure to spread the news to family and friends who are also eligible to receive it and recommend it to other women within our social network and contact. 'People's perception on my daughter receiving the vaccine does not really matter as it is a matter of life and death. Also, people shouldn't associate cancer with corrupt moral standards. Although we are hearing about the HPV for the first time to be linked with cervical cancer but at that I think HPV vaccine will not encourage promiscuity among adolescent girls as the benefit outweighs any negative effect"' The people have a high spirits toward the administration of the vaccine and do not mind people's perception about their decision to the take the vaccine for themselves or for their daughters as they are more concerned about the benefit than side gossips. Most of them think the HPV vaccine will save the lives of the adolescent girls and they are ready to allow their daughters take the HPV vaccine, if it available, accessible and affordable.

\subsubsection{Respondents Attitude of respondent toward the uptakes of vaccination}

The respondents 'responses to the attitudinal statements are presented in Table 5.1 .0 Two hundred and forty -three (75.9\%)of the respondents agreed with the statement that Young girls between the age of $10-16$ years must be vaccinated against HPV vaccination. While 50 (5.6\%) disagreed. Two hundred and twenty -six respondents (70.6\%) agreed to the statement that Unmarried young girls need to be vaccinated. while 46(14.6\%)disagreed. Two hundred and sixty-two (82.0\%) agreed to the statement that sexually active adolescent need to have HPV vaccine at some point in their life time. While 71 (12.4\%)disagreed. Furthermore, 300 (93.7\%) were of the disposition that HPV vaccine could dramatically reduce the levels of cervical cancer while 10 (68.5\%)of the respondents disagreed with this statement. Slightly less than half (140 or $43.7 \%$ )of the respondents were of the disposition that The HPV vaccination will encourage promiscuity among young girls while 156 (48.9\%)disagree with the statement. Seventy- eight (24.3\%) respondents agreed to the statement that HPV vaccine will affect the reproductive system / fertility of the girls while 225 (70.3\%) disagreed. In addition sixty - seven (20.9\%) agreed that Receiving the vaccine show that the girl is immoral while 284 (77.5\%)disagreed to that statement. The attitudinal level was assessed by assigning three points to a response that indicated positive attitude and zero to a response that indicated a negative attitude. A 21 -point scale was generated and respondents that scored $1-9$ points were categorized as having negative attitude while those with 12- 21 points were categorized as having positive attitude. Overall mean attitude score was $18.1 \pm 5.2$ out of 21 (Table 5.1). Respondents who had positive attitude were 298 (93.2\%). The peripheral stratum had the least number of respondents with negative attitude 22 (6.7\%).

Table 5.0 Attitude of respondent toward the uptakes of vaccination

\begin{tabular}{|l|l|l|l|l|}
\hline S/N & VARIABLES & Agree & Disagree & Undecided \\
\hline 1 & $\begin{array}{l}\text { Young girls between the ages of 10 - 16 } \\
\text { years must be vaccinated against HPV } \\
\text { vaccination. }\end{array}$ & $243(75.9 \%)$ & $50(15.6 \%)$ & $22(8.4 \%)$ \\
\hline 2 & $\begin{array}{l}\text { Unmarried young girls need to } \\
\text { vaccinated }\end{array}$ & $226(70.6 \%)$ & $46(14.6 \%)$ & $48(15.6 \%)$ \\
\hline 3 & $\begin{array}{l}\text { Sexually active adolescent need to have } \\
\text { HPV vaccine at some point in her life } \\
\text { time }\end{array}$ & $262(82 \%)$ & $39(12.4 \%)$ & $19(5.9)$ \\
\hline 4 & $\begin{array}{l}\text { HPV vaccine could dramatically reduce } \\
\text { the levels of cervical cancer? }\end{array}$ & $300(93.7 \%)$ & $10(3.1 \%)$ & $10(3.1 \%)$ \\
\hline 5 & $\begin{array}{l}\text { The HPV vaccination will encourage } \\
\text { promiscuity among young girls }\end{array}$ & $140(43.7 \%)$ & $156(48.95)$ & $8(2.5 \%)$ \\
\hline
\end{tabular}


South American Journal of Public Health

Special Edition May 2016

\begin{tabular}{|l|l|l|l|l|}
\hline 6 & $\begin{array}{l}\text { HPV vaccine will affect the } \\
\text { reproductive system /fertility of the girls }\end{array}$ & $78(24.3 \%)$ & $225(70.3 \%)$ & $9(3.0 \%)$ \\
\hline 7 & $\begin{array}{l}\text { Receiving the vaccine show that the girl } \\
\text { is immoral }\end{array}$ & $67(20.1 \%)$ & $284(77.5 \%)$ & $5(1.5 \%)$ \\
\hline
\end{tabular}

Table 5.1 Attitude grade of respondents

\begin{tabular}{|l|l|l|}
\hline Attitudinal score & Frequency & $\mathbf{\%}$ \\
\hline Positive value (12-21 points) & 298 & 93.2 \\
\hline Negative value (1 -9 points) & 22 & 6.8 \\
\hline TOTAL & 320 & 100.0 \\
\hline
\end{tabular}

\subsubsection{Communication Strategy for the dissemination of HPV vaccine}

The channel information is passed across in the community will determine if the information will get to the targeted population or not and at the correct state. The channel used in receiving health (immunization) information in the past in the community was identified as follows: Radio, T V (BCOS/NTA), primary health care center in the community, schools and outreach program in the market place, social network like: landlord - Tenants relationship, ethnic group and clan association and other networks like market women association and trader association, the use of community structure / leadership like the traditional leaders and religious leaders were also identify as medium of passing information on immunization in the community. The previous immunization especially in the case of polio vaccine the communication strategy/channel used include the use of community sensation among women in the market place and at the health center were vaccine were made available. They had the vaccine permanently at the health care center were people are expected to go and take it. But the patronage is usually low until there is a specific intervention to increase awareness on the vaccine. 58 But experience from yellow fever and Meningitis vaccine for the daughters shown that use of school and learning center was used and it work best. The health care worker come to the assembly ground talk on the important of taking the vaccine after due approval from the principle, ministry of Education and ministry of health; they were all vaccinated on the assembly ground. Although, some women are of the opinion that the channels of communication to be employ for disseminating information on vaccine depend on the methods that is appropriate for giving the vaccine. Like the Tetanus vaccine is normally given in the health center for mothers during antennal clinic so if a woman is pregnant she cannot be given the vaccine in the community. Majority of the mothers think HPV vaccination program for the community people will work best using the community leaders, religious leaders and social network. Few others think the use of mass media like the $\mathrm{T} \mathrm{V} /$ Radio and community outreach by the health worker will also be effective. Some others suggest the use of social networks and groups, churches and mosque, women groups will also be effective for the HPV vaccine. They also recommend that the government should use community driven approached for the HPV vaccine not the health center based approaches use for most cervical cancer service like the Pap smear as it has not work. Majority of respondent desire more information on the side effect of the vaccine if any, where to get the HPV vaccine when made available, the cost of the vaccine and long term effect.

\subsubsection{Summary of findings}

Based on the result from the data analysis from the FGDs and Semi Structure interviews the following findings emerged;

1. It was observed that there was low level of awareness on cervical cancer in the community among the mothers and daughters especially knowledge on the preventive 59 approaches to cervical cancer like HPV vaccine, but the knowledge and awareness of cancer generally was high 
2. It was discovered that they have be expose to a lot of immunization against different diseases in the past by both the mothers and the daughters

3. It was observed that high desire and wiliness to received the HPV vaccine was express by both the mothers and daughters

4. It was discovered that majority of the mothers had positive experience from previous immunization, but few others are aware of negative experience of immunization based on other people experience.

5. There is no significant different between their level of awareness of cervical cancer and the desire to take the HPV vaccine. Even though the level of awareness of cervical cancer was low the desire to take the vaccine was high. This may be due to the awareness of cancer as a deadly disease.

6. There is a significant relationship in the experience from previous immunization and the desire to take the HPV vaccine, this relationship is a positive influence.

\section{Discussion of result}

\subsection{Introduction}

This chapter presents the detailed discussion of finding of the study, hypothesis by and the summary of the study from the beginning to the end. Conclusion were reached based on the finding, recommendation were offered and suggestion for further studies highlighted

\subsection{Respondents' demographic characteristics}

Demographic characteristic of respondents in Akinyele local government show that majority (65\%) of the mothers are 36 years of age which will be explained from their daughter age were $(69 \%)$ are 13 years. The level of awareness and desire to take vaccine was more expressed by the older adolescent as compare to the younger one. Even though age could give explanation for that, but the educational attainment could also be a good explanation for that. The predominant form of occupation in the community is farming as it a farm settlement. Most of the dweller in the community comes from different part of Oyo state to settle there during farming seasoning while some of them return back to the urban part of the state during dry seasons these explain why most of the women do not have a formal education. The cultural practice in that community seem to have strong effect in the perception of the people as even those that had some form of education like primary school (10\%)secondary school certificate $(10 \%)$ and 5\% had NCE certificates their views about the different issues did not show any much significant different especially in their attitude toward the uptake of the vaccine and level of awareness of cervical cancer and HPV vaccine. The majority of the mothers indicated they were married, but that did not influence their decision to allow their daughter to the vaccine as none of them talk about asking taking permission from their husband before they can present their daughter for the vaccine. Economic status of the mothers has a strong influence in allow their daughter to take the vaccine. Even though majority of the mothers are petty traders in the community with commodities like fish selling, selling of provision, hairdressing and fashion designing. A few others are civil servants and clerical staff like typists, attendants and cleaners in various organizations. But majority of the mother identified cost as a barrier to receiving the vaccine if not made free by the government. Also the choice of the use of community based approach in administration of the vaccine could have been due to the nature of the economic source of livelihood which is predominately in the community. On the number of children ever had (parity)by the mothers $67 \%$ of the mothers have 5 children and above while $27 \%$ of them have between 4 and 3 children and $6 \%$ have 2 children. There was no significant different in the decision to take the vaccine and the parity of the mothers. In the choice of the form communication in dissemination of HPV vaccine the mothers prefer the use of community approach and social network due to their economic livelihood while the adolescent girls prefer the use of schools environment because majority of them are student. 
South American Journal of Public Health

Special Edition May 2016

\subsection{Awareness of cervical cancer and HPV Vaccination among the mothers and daughters}

One major finding is that the mothers have high awareness about cancer generally especially breast cancer, but majority of the women have low level of awareness on cervical cancer as just a few of the women indicated to have heard about cervical cancer. Similarly the national HIV/AIDS and reproductive health survey (NARHS 2003)revealed that only $12.8 \%$ of women and $4.3 \%$ of men have ever heard about cancer cervix. This was also affirmed by (Daramola 2001) in her study of the awareness of screening producer of carcinoma of the cervix smear amongst health service user in Lagos, Nigeria found that only $26.2 \%$ of them were aware of cervical cancer. Although few mothers have some form of awareness about cervical cancer including signs and symptom. Even though the symptom listed by the women can be notice in the advance stage of cervical it can also be seen as indication of others STIs.

Also in terms of prevention and treatment even thought majority of the mothers know that cancer is deadly and do not have cure they still feel the signs and symptoms identify can be managed with a visit to chemist as against going to the hospital for proper examination. The reason for this was not far fetch as they confirmed going to big hospital like UCH is very expensive and time wasting. This explains the late and advance presentation of cervical cancer in the teaching hospital. According, (Dr. Eguwuon, NCCP) majority of women present late when little opportunity for curative treatment are available and no there are no access to palliative care. Cervical cancer is not a common name in the community as it was observed that there was perceived fear among the women in discussing issues around cancer generally as they perceived it as a deadly disease and it is an areas they will render not want to talk about. But majority of women agreed that breast cancer is common in the community as it has been observed among some women in the community and also is awareness on radio and health care center on breast cancer. Some other finding was that the mothers agreed that cancer of any kind create a major disease burden on the family members and relatives in terms of monetary expenses and time spend in the hospital for treatment and cervical cancer will pose more burden because it affect the health of women as they are major economic source for the family.

Furthermore hypothesis testing also showed that there is no significant different between awareness of the cervical cancer and the desire for uptake of the vaccine. This result is surprising as one would think as the level of awareness is low the desire for uptake will be low also. This assumption was based on the premise that health seeking behavior like immunization will be based on the level of awareness of the disease but it was prove otherwise. The possible reasons for this result is the negative health impact of some women suffering from other forms of cancer they have see in the community and also cancer is consider a deadly disease in the community so they will consider any form of prevention made available to them.

Their main source of the information on health related issues in the community are; through the primary health center in the community, the mass media which include TV/Radio and outreach programs in strategy place. Other key finding that came was that few of the mothers think living to too young adolescent girls will encourage promiscuity among the girls even though that should be considered was not specified. But majority of the mothers believe the sexual behavior of adolescent girls cannot be determined as they engage in early pre marital sexual affair. Also literature shown that in Nigeria early sexual debut has been reported among adolescent girls at age 12 (Ajayi and Adewole, 1998). Finding also shown that that the mothers believe that vaccination is important and should be encourage by all relevant stakeholders especially the HPV vaccine that can save the life of our younger generation of women from be infected with HPV virus which causes cervical cancer that is very deadly. 


\subsection{Experience of mothers from previous vaccination utilization and desire for uptake of the HPV vaccine}

Finding from the shown that majority of the women and their daughter have some form of experience from previous vaccination in the past. Most of the mothers have their vaccination during the antennal clinic during their last pregnancy while the daughter can also tell of the experience they had from vaccine they took in school which was mainly yellow fever and meningitides vaccine. But they can talk based on the vaccine they took as a child as they cannot remember experience from such vaccine only their mothers can talk on the experience of the childhood vaccination experience for their daughter. Their experience from previous vaccination was generally positive although some of women had negative experience from the childhood vaccination for their daughters. Hypothesis testing shown there is association between their previous immunization experience and the decision for uptake HPV vaccine. This null hypothesis was rejected as the association that exists between the variable shows to be positive. This was because majority of the mothers have good understanding and the important of vaccination in the community as they understand the cost effectiveness of vaccine to treatment of disease. Acceptance of HPV vaccine or any other vaccine without prejudice was easy as they already know the important of vaccination program. The other reason was the perceived deadly effect and nature of cancer (especially breast cancer which they are well familiar) so anything available to prevent such disease will be welcome. Even the desire for uptake of the vaccine is high and was well expressed by both mothers and adolescent girls but the need to make adequate information available for the mothers before they allowed their daughters to the vaccine was clear bring out in their recommendation. They seek to have clear information on the efficacy of and effectiveness of the vaccine. They demand to know if there is any side effect from the vaccine especially immediate reaction so they prepare for it management so as to prevent taken unaware. Furthermore it was observed that there was reduced awareness on the important of vaccine among the daughters especially among the younger daughters (10 - 13 years)while those between $14-16$ years of age have some form of information on the important of vaccination this could be as a result of their age. One majority finding that came out strong was that at the family level was strong influence of mothers in the vaccination decision in the family. As the mothers never talk about taking permission from their husband or family relative before taking decision on vaccination also when the daughters were asked if they will take the vaccine majority said it will depend on their mother decision. Although some of the daughters said it depend on their mothers decision as money might be involve and health care decision are taken by their parent especially the mothers.

\subsection{Implication for health promotion and Education}

The role of health education and promotion is very important in help the people take health seeking behavior like vaccination. Health education as the first essential element of primary health care (PHC) aims at the developing the capacity of the people act in their own interest. Beiger in 1996 defined health education as any combination of learning activities that promote voluntary adaptation in health and health related behaviors. According to (W.H.O 1973)health education helps people to take the right decision on health matters by providing them with experience which will enable them to develop the kind of understanding and insight that will facilitate individual and community action. The definition implies the confidence that people will take constructive health action when they fully understand the implication of that action, provided it does not conflict with others that are more important. When adequate information is provide for the people there are people of special influence in any community that determine can also influence decision to the take vaccine. The people that wield a lot of influence are sometimes called opinion leaders. Opinion leaders may or may not be formal leaders. Opinion leaders may be chiefs, pastors, teachers or retired civil servants or soldiers. It is important to find out who the opinion leaders are and what they think the needs of the communities are. These people are capable of influencing the opinions of others about 
South American Journal of Public Health

Special Edition May 2016

any issue in the community (Adapted from Hart, 1992). It is essential to identify good leaders and involve them with other community members in the definition and solution of problem. Leadership and participation however, will vary among communities, depending on the issue at stake and the kinds of problems.

Findings from this study shown that there are some commonly identified stakeholders that had played key roles in previous vaccination program in the community. They include: Traditional leaders which include the bale, iyelodes and balogus, health care professional in the community which include those at the primary health care centers and community health workers, the religious leaders which include pastors and Imam, Leaders of social network which include women groups and associations of Landlords, Clan meeting and ethnic group meeting. For an effective vaccination program in the community these people need to be vital involved at all levels. The way information is passed across in the community will determine if the 66 information will get across to the targeted population or not in the correct state. The health promotion approaches identified in passing information across in the community include the use of the town crier, Community theatre, School Teacher and Religious leaders. $\mathrm{Bu}$ the channel and medium that should be used include: Radio, primary health clinic, community sensitization and outreach program, also through their community leaders and religious heads as identified as an effective channel. The best form in which the information can be passed across to them the community includes; through the health care worker in the community in collaboration with community leaders, social network which include the associations like Landlord - tenet association and market women association as they will be the most effective in this community. In conclusion this study indicates that although attitudes towards vaccine are broadly positive, the age of vaccination is likely to be a contentious issue and some parents have concerns about encouraging risky sexual behavior. Clear communication will be key in making parents understand the reason for vaccinating girls early. Many women felt that they would want to discuss the vaccination with their daughters, and that this would be problematic below a certain age. Some felt that below the age of 10 or 11, girls have not had much, if any; sex education at school, and that therefore discussing an STI with them would be difficult.

\section{Conclusion}

In conclusion this study indicates that although attitudes towards vaccine are broadly positive, the age of vaccination is likely to be a contentious issue and some parents have concerns about encouraging risky sexual behavior. Clear communication will be key in making parents understand the reason for vaccinating girls early. Many women felt that they would want to discuss the vaccination with their daughters, and that this would be problematic below a certain age. Some felt that below the age of 10 or 11, girls have not had much, if any;sex education at school, and that therefore discussing an STI with them would be difficult.

\section{Recommendations}

- There is need for the government create more awareness of his new vaccines and pass correct information about the benefit of the vaccine uptake. It is highly recommended for the government to use community driven approached for the HPV vaccine not the health center based approaches use for most cervical cancer service like the Pap.

- Clear communication on the benefit of the vaccine will be key in making parents understand the reason for vaccinating girls early. Many women felt that they would want to discuss the vaccination with their daughters, and that this would be problematic below a certain age.

- The use of health workers to carry out community sensitization will be a great resource in the information diseminnation because of the high community respect they enjoy in working with members of the communities. 
- The channel of communication within member of the community can also determine how far reached the information can go. The using the health care worker has the sensitizer in the community in collaboration with community leaders, religious leaders, some social network which include the associations like Landlord - tenet association and market women association will be the most effective approach in this community

\section{References}

[1.] Abogunrin, A. J. (2004). Sexual behaviour, condom use, and attitudes towards HIV/AIDS among school-going adolescents in Nigeria. Unpublished Ph.D dissertation, University of Ilorin, Ilorin.

[2.] Abraham S: Vaginal and speculum examination in medical curricula. Aust N Z J Obstet Gynaecol 1995, 35:56-60.

[3.] Adab P. Screening for cervical cancer in Hong Kong [abstract]. Presented at the Fifth Hong Kong International Cancer Congress; 1998 Nov 10; Hong Kong

[4.] Adegoke, A. A. (2003). Adolescents in Africa: Revealing the problems of teenagers in a contemporary African society. Ibadan: Haddasah Publishing.

[5.] Adegoke, A. A. (2004).Adolescence and adolescent problems in schools. In Adeyemi Idowu, Guidance and counselling in education. Ilorin: Indemac Publishers (Nig.) Ltd.

[6.] Adekeye, O. A. (2005). Adolescents and the HIV pandemic. Ilorin Researcher: Journal of the Postgraduate Students Association, University of Ilorin. 3 (1): 23-28.

[7.] Adekeye, O. A. (2009). HIV Voluntary Counselling and Testing for Young People: The antidote for a healthy and positive living in Nigeria. The Counsellor: 25 (1)

[8.] Adewole IF, Benedet JL, Brian TC, Fallen M. Evolving a strategic approach to cervical cancer control in Africa. Gynecologic Oncology Vol 99, Issue 3, Suppl 1, Dec 2005, pages S209-S212.

[9.] Ajayi I. O. and Adewole I. F. (1998). Knowledge and attitude of general outpatient attendants in Nigeria to cervical cancer screening. Cent. Afr. J. Med. Vol.44, No.2:41-43.

[10.] Akinboye, J. O. (1985). Guidance and counselling strategies for handling adolescents and youth problems, (2nd ed.), Ibadan: Claverianum Press.

[11.] Alliance for Cervical Cancer Prevention (ACCP): Planning and Implementing Cervical Cancer Prevention and Control Programs: A Manual for Managers. Seattle; 2004:24-28.

[12.] Amazigo, U; Silva, N.; Kaufman, J. and Obikeze, D.S. (1997). Sexual activity and contraceptive knowledge and use among in-school adolescents in Nigeria. International Family Planning Perspectives, 23, 28-33. Retrieved on 8th May 2010 from www.popline.org/docs/1183/121448.html.

[13.] American Cancer Society, Detailed Guide: Cervical Cancer; The Centers for Disease Control and Prevention, United States Cancer Statistics: 2002 Incidence and Mortality, 2005. 69

[14.] Araoye, M. O and Fakeye, O. O. (1998). Sexuality and contraception among Nigerian adolescents and youth. African Journal of Reproductive Health. 2 (2), 11-14. Retrieved on 5th March 2010 from www.advocatesforyouth.org/PUBLICATIONS/factsheet/fsnigeria.htl

[15.] Armstrong C. ACIP Releases Recommendations on Quadrivalent Human Papillomavirus Vaccine Am FAM Physician. May 1, 2007; 75(9); 1391-1380.

[16.] Ayiga, N.; James, P.M. Ntozi, Ahimbisibwe, F E.; Odwee, J. and Okurut, F. N. (2000). Deaths, HIV testing and sexual behaviour change and its determinants in northern Uganda. Department of Population Studies, Makerere University, Kampala, Uganda. Retrieved on 5th May 2010 from http://htc.anu.edu.au/pdfs/resistances_ch6.pdf

[17.] Ayinde, A. E., Adewole, I. F. \& Babarinsa I. A. (1998) Trends in Cervical Cancer Screening in Ibadan Nigeria. A four-year review. W. Afr. J. Med. Vol. 17: No.1:25-30.

[18.] Babarinsa, I. A. and Adewole, I. F. (1998). Knowledge and attitude to utilization of cervical cytology screening by female workers in a Nigerian Teaching Hospital. Nig. Med. Pract. Vol. 35; No: 48-52.

[19.] Babarinsa, I. A.; Akang, E. E. U. \& Adewole I. F. (1998) Pattern of Gynecological Malignancies at Ibadan Cancer Registry (1976-1996). Nig. Qt. J. Med.8:103-106. 
South American Journal of Public Health

Special Edition May 2016

[20.] Brabin L, Roberts SA, Farzaneh F, Kitchener HC. Future acceptance of adolescent human papillomavirus vaccination: a survey of parental attitudes. Vaccine. 2006;24:3087-94: 10.1016/j.vaccine.2006.01.04

[21.] Bulletin of the World Health Organization. Controversial new vaccine to prevent cervical cancer 2006;

[22.] Cavalli F, Hansen HH, Kaye SB. Textbook of Medical Oncology. Martin Dunitz Ltd; 1997.

[23.] Center for Biologics Evaluation, Product Approval Information - Licensing Action, June 2006. The Centers for Disease Control and Prevention, HPV Vaccine Questions and Answers, June 2006 Ibid.

[24.] Chan DW. Sex misinformation and misconceptions among Chinese medical 15 students in Hong Kong. Med Educ 1986; 20:390-8. 20. Baumrind D. The average expectable environment is not good enough: a response to Scars. Child Dev 1993; 64:1299-317.

[25.] Chirenje MZ, Rusakaniko S, Kirumbi L, Ngwall WE, Makula-Tlebere P, Kaggwa S, Mpanju-Shumbusho W, Makoa L: Situational analysis for cervical cancer diagnosis and treatment in East, Central and southern African 2005.

[26.] Chirenje ZM, Chipato T, Kasule J, Rusakaniko S, Gaffikin L, and Blumenthal P, Sangvi H: Visual inspection of the cervix as a primary means of cervical cancer screening: results of a pilot study. Cent Afri J Med 1999, 45:30-33. 70

[27.] Coombes R. Life saving treatment or giant experiment? BMJ. 2007; 334:721-723: 10.1136/bmj.39164.510127.AD

[28.] Cronje HS, Cooreman BF, Beyer E, Bam RH, Middlecote BD, and Divall PD: Screening for cervical neoplasia in a developing country utilizing cytology, cervicography and the acetic acid test. Int J Gynaecol Obstet 2001, 72:151-7.

[29.] Cronje HS, Parham GP, Cooreman BF, de Beer A, Divall P, Bam RH: A comparison of four screening methods for cervical neoplasia in a developing country. Am J Obstet Gynecol 2003, 188:395-400.

[30.] Dell DL, Chen H, Ahmad F, Stewart DF. Knowledge about Human Papillomavirus among adolescents. Obstet Gynecol. 2000; 96:653-6: 10.1016/S0029-7844(00)01009-7.

[31.] Diaz ML. Human Papilloma Virus - Prevention and Treatment. Obstet Gynecol Clin North Am. June 2008; 35(2); 199-21. NCCN Clinical Practical Guidelines in Oncology: Cervical cancer. 1st ed. 2008. Accessed June 10, 2008

[32.] Dinh TA, Rosenthal SL, Doan ED, Trang T, Pham VH, Tran BD, Tran VD, Bao Phan GA, Chu $\mathrm{HKH}$, Breitkopf CR. Attitudes of Mothers in Da Nang, Vietnam toward a Human Papillomavirus Vaccine. Journal of Adolescent Health. 2007; 10:1016.

[33.] Editorial. Should HPV vaccines be mandatory for all adolescents? The Lancet. 2006;368

[34.] Editorial. Who should be vaccinated against human papillomavirus? The Lancet Infectious Diseases. 2006; 6:1: 10.1016/S1473-3099(05)70301-7.

[35.] Elovainio L, Nieminen P, Miller AB: Impact of cancer screening on women's health. Int J Gynaecol Obstet 1997, 58:137-147. MacGregor JE: Screening for cervical cancer. In Contemporary Obstetrics and Gynecology. Edited by: Chamberlain G. London: Butterworth 1988:343-356.

[36.] Ezem B. U 2007 Awareness and uptake of cervical cancer screening in Owerri, South- Eastern Nigeria Department of Obstetrics and Gynecology, Imo State University Teaching Hospital, Orlu, Nigeria

[37.] Fawzy FI, Coombs RH, Gerber B. Generational continuity in the use of substances: the impact of parental substance use on adolescent substance use. Addict Behavior 1983; 8:10914.

[38.] Friedman AL, Shepeard H. Exploring the knowledge, attitudes and beliefs, and communicating preferences of the general public regarding HPV: findings from CDC focus group research and implications for practice. Health Education Behaviour. 2007; 34:471-485: 10.1177/1090198106292022. 71

[39.] Gajalakshmi CK, Krishnamurthi S, Ananth R, and Shanta V: Cervical cancer screening in Tamilnadu, India: a feasibility study of training the village health nurse. Cancer causes control 1996, 7:520-524. 
[40.] Goldie SJ, Kohli M, Grima D, et al. Projected clinical benefits and cost-effectiveness of a human papillomavirus 16/18 vaccine. J Natl Cancer Inst 2004; 96:604-15.

[41.] Harper DM, Franco EL, Wheeler C, Ferris DG, Jenkins D, Schuind A, Zahaf T, Innis B, Naud P, De Carvalho NS, Roteli-Martins CM, Teixeira J, Blatter MM, Korn AP, Quint W, Dubin G. GlaxoSmithKline HPV Vaccine Study Group. Efficacy of a bivalent L1 virus-like particle vaccine in prevention of infection with human papillomavirus type 16 and 18 in young women: a randomized control trial. The Lancet. 2004; 364:1757-1765. 10.1016/S0140-6736(04)17398-4.

[42.] Harper DM, Franco EL, Wheeler C, Ferris DG, Jenkins D, Schuind A, et al. Efficacy of a bivalent L1 virus-like particle vaccine in prevention of infection with human papilloma virus types 16 and 18 in young women: a randomized controlled trial. Lancet 2004, 364 (9447), 1757-1766.

[43.] Hoch mans A, Ratzkowski E, Schrieber H. Incidence of carcinoma of cervix in Jewish women in Israel. Br J cancer 1955; 9:358 - 364).

[44.] Holcomb B, Bailey JM, Crawford K, Ruffin MT. Adults knowledge and behaviors related to human papillomavirus infection. 2004; 17:26-31.

[45.] Kahn JA, Rosenthal SL, Hamann T, Bernstein DI. Attitudes about human papillomavirus vaccine in young women. Int J STD AIDS 2003; 14:300-6.

[46.] Kandel DB, Wu P. The contributions of mothers and fathers to the intergenerational transmission of cigarette smoking in adolescence. J Res Adolescent 1995; 5:225-52.

[47.] Kapiga SH, Msamanga GI, Spiegelman D, Mwakyoma H, Fawzi WW, Hunter DJ: Risk factors for squamous intraepithelial lesions among HIV-1 seropositive women in Dares Salaam, Tanzania. Int J Gynaecol Obstet 1999, 67:87-94.

[48.] Koutsky LA, Ault KA, Wheeler CM, Brown DR, Barr E, Alvarez FB, Chiacchierini LM, Jansen KU. A controlled trial of a human papillomavirus type 16 vaccine. The New England Journal of Medicine. 2002; 347:1645-51. 10.1056/NEJMoa020586.

[49.] Koutsky LA, Ault KA, Wheeler CM, et al. A controlled trial of a human papillomavirus type 16 vaccine. N England J Med 2002; 347:1645-51.

[50.] Lehtinen M, Apter D, Dubin G, Kosunen EL, Kyha-Osterlund L, Lunnas T, Luostarinen T, Niemi L, Palmroth J, Petaja T, Rekonen S, Salmivesi S, Siitari-Mattlia M, Svartsjo S, 72 Tuomivaara L, Viikki M, Pukkala E, Paavonen J. Enrolment of 22,000 adolescent women to cancer registry follow up for long term human papillomavirus vaccine efficacy: guarding against guesses. International journal of STD and AIDS. 2006; 17:517-521. 10.1258/095646206778145550.

[51.] Leroy V, Ladner J, DeClercq A, Meheus A, Nyiraziraje M, Karita E, Dabis F: Cervical dysplasia and HIV type 1 infection in African pregnant women: a cross sectional study, Kigali, Rwanda. The Pregnancy and HIV Study Group (EGE). Sex Transm Infect 1999, 75:103-106.

[52.] Lo B. HPV vaccine and adolescents' sexual activity. BMJ. 2006; 332:1106-1107. 10.1136/bmj.332.7550.1106.

[53.] Lowndes CM, Gill OM. Cervical cancer, human papilloma virus and vaccination. BMJ. 2005; 331:915-916: 10.1136/bmj.331.7522.915.

[54.] Lowndes CM. Editorial review: Vaccines for cervical cancer. Epidemiology Infect. 2006; 134:112. $10.1017 / \mathrm{S} 0950268805005728$.

[55.] Maggwa BN, Hunter DJ, Mbugua S, Tukei P, Mati JK: The relationship between HIV infection and cervical intraepithelial neoplasia among women attending two family planning clinics in Nairobi, Kenya. 16. AIDS 1993, 7:733-738.

[56.] Mahlck CG, Jonsson H, Lenner P: Pap smears screening and changes in cervical cancer mortality in Sweden. Int J Gynaecol Obstet 1994, 44:267-272.

[57.] Marlow LAV, Waller J, Wardle J. Parental attitudes to pre-pubertal HPV vaccination. Vaccine. 2007; 25:1945-1952. 10.1016/j.vaccine.2007.01.059.

[58.] Martin D. Health Reporter: Daily Mail. National Newspaper, UK. p. 11. Saturday May 5, 2007. [59.] Mati JK, Mbugua S, Wanderi P: Cervical cancer in Kenya: prospects for early detection at primary level. Int J Gynaecol Obstet 1994, 47:261-267.

[60.] McIntyre P. Finding the viral link: the story of Harald Zur Hausen. Cancer World. 2005. 
South American Journal of Public Health

Special Edition May 2016

[61.] Megan E. Roberts, BA Meg Gerrard, PhD, Rachel Reimer, PhD, Frederick X. Gibbons Mother-Daughter Communication and Human Papillomavirus Vaccine Uptake by College Students (Published online April 12, 2010PEDIATRICS (doi:10.1542/peds.2009- 2888)

[62.] Merck, Merck to Create New Patient Assistance Program for Vaccines, May 26, 200663. Merck, Merck Vaccine Patient Assistance Program, September 2006. 73

[64.] Mirembe F: The changing pattern of carcinoma cervix in Uganda. In Proceedings of the Scientific Conference of the Association of Obstetricians of Uganda: International Conference Centre, Kampala, Uganda, 22-23 Jan., 1993. Association of Obstetrician and Gynecologists Uganda (AOGU); 1993:54-61.

[65.] Mmiro FA: Gynecology and oncology in Africa. J Obstet Gynaecol E Centr Afr 1987, 6:66-68.

[66.] Morris M, Tortollero-Luna G, Malpica A, et al.: Cervical intraepithelial neoplasia and cervical cancer. Obstet Gynecol Clin North Am 1996, 23:347-410.

[67.] National Vaccine Information Center, State Exemptions, June 2006. Ibid.Sprigg, P. July 15, 2006.

[68.] Noakes K, Yarwood J, Salisbury D. Parental response to the introduction of a vaccine against human papilloma virus. Hum Vaccin. 2006; 2:243-8.

[69.] Ogilvie GS, Remple VP, Marra F, McNeil SA, Naus M, Pielak KL, Ehlen TG, Dobson SR, Money DM, Patrick DM. Parental intention to have daughters receive the human papillomavirus vaccine. CMAJ. 177:1506-12. 2007 Dec 4.

[70.] Olamijulo J, Duncan ID: Is cervical cytology screening of teenagers worthwhile? BrGynaecol Obstet 1995, 102:515-516.

[71.] Olshen E, Woods ER, Austin SB, Luskin M, Bauchner H. Parental acceptance of the human papillomavirus vaccine. Journal of Adolescent Health. 2005; 36:124. 10.1016/j.jadohealth.2004.11.062. [72.] Parkin D. M. (2000) Personal Communication, IARC .Planning Appropriate Cervical Cancer Programs. 2nd Edition 2000 Program for Appropriate Technology in Health (PATH).

[73.] Parkin DM, Ferlay J, Hamdi-Cherif M, Sitas F, Thomas JO, Wabinga H, Whelan SL: Cancer in Africa, epidemiology and prevention. In IARC Scientific Publication, No 153. IARC Press Lyon, France; 2003:167-179. 268-275.

[74.] Peckham, Pinedo, Veronesi Oxford textbook of Oncology sections 8-20. Vol. 2. Oxford: Oxford University press; 1995.

[75.] Poland GA, Jacobson RM, Koutsky LA, Tamms GM, Railkar R, Smith JF, Bryan JT, Cavanaugh $\mathrm{PF}$, Jansen KU, Barr E. Immunogenicity and reactogenicity of a novel vaccine for human papillomavirus 16: a 2-year randomized controlled clinical trial. Mayo clinic proceedings. 2005;80:601-61074

[76.] Poland GA, Jacobson RM, Koutsky LA, Tamms GM, Railkar R, Smith JF, Bryan JT, Cavanaugh $\mathrm{PF}$, Jansen KU, Barr E. Immunogenicity and reactogenicity of a novel vaccine for human papillomavirus 16: a 2-year randomized controlled clinical trial. Mayo clinic proceedings. 2005; 80:601-610.

[77.] Pro-Family, Pro-Vaccine-But Keep It Voluntary, washingtonpost.com. The Centers for Disease Control and Prevention, Vaccines for Children (VFC) Program, July 19, 2006.

[78.] Raley, J.C., K.A. Follow will, G.D. Zimet, et al. September-December 2004. Gynecologists' Attitudes Regarding Human Papilloma Virus Vaccination: A Survey of Fellows of the American College of Obstetricians

[79.] Riedese I JM, Rosenthal SL, Zimet GD, Bernstein DI, Huang B, Lan D, Kahn JA. Family physicians' attitudes about HPV vaccines. Journal of Adolescent Health. 2005; 36:124- 125. 10.1016/j.jadohealth.2004.11.063.

[80.] Rimal RN. Intergenerational transmission of health: the role of intrapersonal, interpersonal, and communicative factors. Health Education Behaviors 2003; 30:10-28.

[81.] Rose M. Official social classifications in the UK. Guildford: University of Surrey; 1998.

[82.] Ryder AG, Alden LE, Paulhus DL. Is acculturation one-dimensional or bi dimensional? A head-to-head comparison in the prediction of personality, self-identity, and adjustment. J Pers Soc Psychol 2000; 79(1):49-65.

[83.] Southern African countries Bulletin of the World Health Organization 2001, 79:127-132. 
[84.] Steinbrook R. The Potential of Human Papilllomavirus Vaccines. NEJM. 2006; 354:1109- 1112. 10.1056/NEJMp058305.

[85.] The Centers for Disease Control and Prevention, Advisory Committee on Immunization Practices (ACIP), June 2006.

[86.] The Centers for Disease Control and Prevention, HPV and HPV Vaccine - Information for Healthcare Providers, June 2006.

[87.] The Centers for Disease Control and Prevention, HPV Vaccine Questions and Answers, June 2006.

[88.] The Office of Minority Health, Eliminate Disparities in Cancer Screening \& Management, June 30, 2006. The Centers for Disease Control and Prevention, CDC Press Briefing: ACIP Recommends HPV Vaccination, June 29, 2006.

[89.] Villa LL, Costa RL, Petta CA, et al. Prophylactic quadrivalent human papillomavirus (types 6, 11, 16, and 18) L1 virus-like particle vaccine in young women: a randomised 75 double-blind placebo-controlled multicentre phase II efficacy trial. Lancet Oncol 2005; 6:271-8.

[90.] Waller Marlow L, Wardle J. Public awareness that HPV is a risk factor for cervical cancer. Br J Cancer. 2007; 97:691-94: 10.1038/sj.bjc.6603927.

[91.] Woodhall SC, Lehtinen M, Verho T, Huhtala H, Hokkanen M, Kosunen E. Anticipated Acceptance of HPV Vaccination at the Baseline of Implementation: A Survey of Parental and Adolescent Knowledge and Attitudes in Finland. Journal of Adolescent Health. 2007; 40:466-469. 10.1016/j.jadohealth.2007.01.005.

[92.] World Health Organization (WHO). Primary Prevention of Cervical Cancer. WHO, Geneva, October 3-November 2, CAN/85.1 (1985).

[93.] World Health Organization, Comprehensive Cervical Cancer Control: A Guide to Essential Practice, 2006.

[94.] Zach S, Netz Y. Like mother like child: three generations’ patterns of exercise behavior. Fam Syst Health 2007; 25:419-34.

[95.] Zimet GD, Liddon N, Rosenthal SL, Lazcano-Ponce E, Allen B. Psychosocial aspects of vaccine acceptability. Vaccine. 2006;24: S201-209. 10.1016/j.vaccine.2006.06.017. 11. 2006 Canadian statistics [homepage on the Internet]. 2008. Available at: http://www12.statcan.ca/english/census06/ 